\title{
الاتحاد الأوروببي والهجرة غير النظامية: دراسة حالة ليبيا
}

\section{The European Union and Irregular Migration: A Case Study of Libya}

تسلط هذه الدراسة الضوء على المراحل التي تطورت خلالها سياسات الهجرة التي اتبعها الاتحاد الأوروبي.

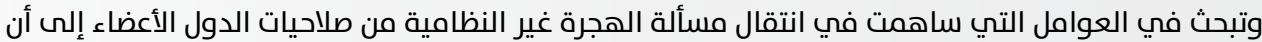

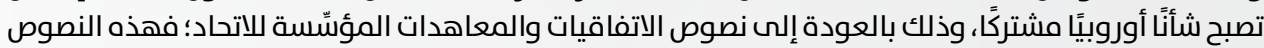
تمثل برنامجَ عملٍ مشتركًا في مجالات إدراّا

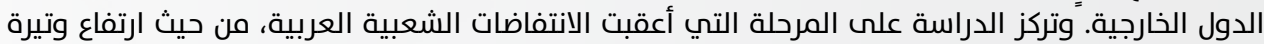

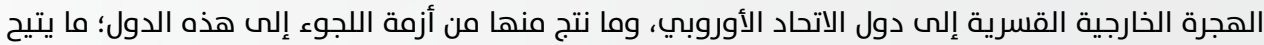

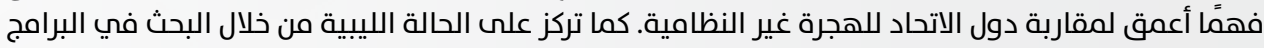

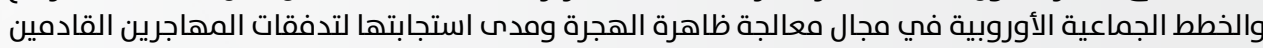
من ليبيا، باعتبارها نقطة انطلاق وساحة عملٍ منظمٍ لشبكات التهريب والإِ التجار بالبشر بعد عامم 2011.

كلمات مفتاحية: الهجرة غير النظامية، الاتحاد الأوروبي، ليبيا، سياسات الهجرة.

This study investigates the developmental stages of European Union migration policy and examines the factors behind the transformation of irregular migration from an individual member state issue to a common European affair. It traces the texts of the agreements and treaties that created the $\mathrm{EU}$ and which represent a program of action for managing and controlling immigration and the movement of individuals between member states and the foreign countries. The research focuses on the period following the Arab popular uprisings and the sharp increase of forced migration to Europe, and the resulting refugee crisis in the EU. European collective programs that address migration are examined to better understand the EU's approach to irregular migration, especially from Libya. The paper looks at plans to deal with the flow of immigrants from Libya, which is a starting point for many migrants and a known home of human smuggling and trafficking networks since 2011.

Keywords: Irregular Migration, European Union, Libya, Migration Policy.

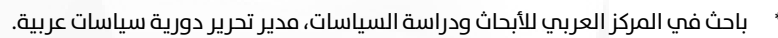
Researcher at the Arab Center for Research and Policy Studies. He is the managing editor of Siyasat Arabiya Journal.

Email:ahmed.hussein@dohainstitute.org 


\section{مقدمة}

تفاقمت ظاهرة الهجرة غير النظامية أو غير القانونية (1) بعد الانتفاضات الشعبية في المنطقة العربية في عام 2011، نتيجة موجة العنف التي مارستها النظم التسلطية في مواجهة الحركات الاحتجاجية، وما رافقها من تعظّل النظام

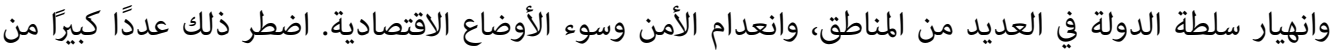
مواطني دول عربية، مثل سورية ومصر والعراق وليبيا، إلى البحث عن ملاذ آمن لهم ولأسرهم. مل تكن المنطقة العربية

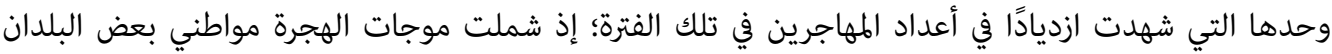

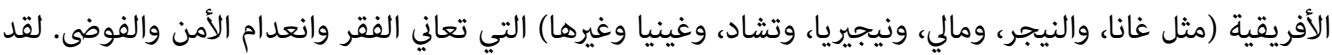

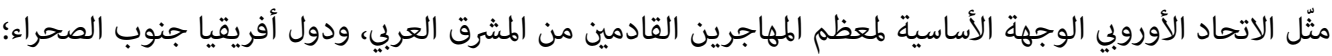
ذلك أن قوانين الاتحاد تسمح بطلب اللجوء الإنساني والسياسي، وتمنح طالبي اللجوء تسهيلات الإقامة وإجراءات

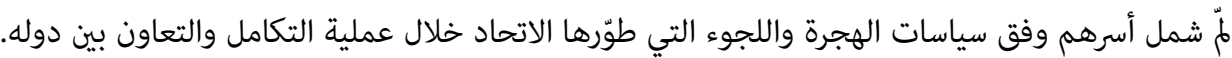
مع تنامي أعداد طالبي اللجوء في دول الاتحاد الأوروبي، تحوّلت ظاهرة الهجرة غير النظامية إلى قضية رأي عام

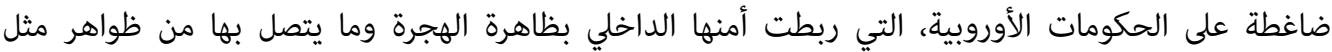
الجريمة والإرهاب والتطرف الديني والعنصرية. تعاملت حكومات دول الاتحاد مع الهجرة باعتبارها معضلة أمنية Security Dilemma المتطرف، التي أذكت الشعور القومي واستثمرت حالة الاحتجاج المجتمعي على سوء الأوضاع الاقتصادية في إدراج الهجرة ضمن برامجها ودعاياتها لتحقيق مكاسب سياسية داخلية. فقد وظف زعماء شعبويون مثل ماتيو سالفيني Matteo Salvini فرنسا، وسيباستيان كورتز Sebastian Kurz زعيم حزب الشعب النمساوي، قضيةً الهجرة في إذكاء الخوف والكراهية وحشد الدعم في الانتخابات.

إن تصنيف الأحزاب والحركات اليمينية الشعبوية في أوروبا المهاجرين، باعتبارهم خطرًا يهدد الاستقرار الداخلي

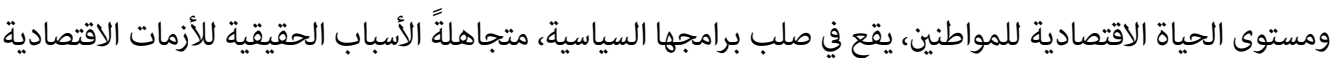
في منطقة اليورو التي تعود إلى فترة سبقت ازدياد وتيرة الهجرة غير النظامية. لقد تحولت الخطابات الشعبوية في

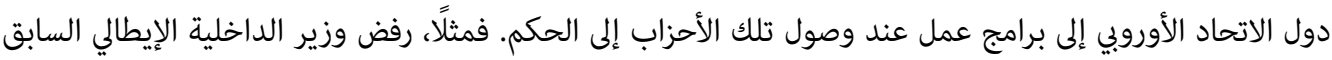

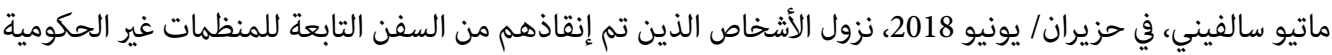

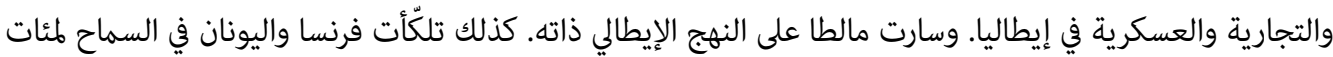

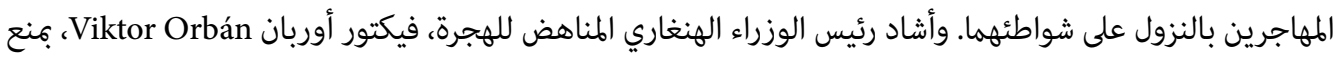

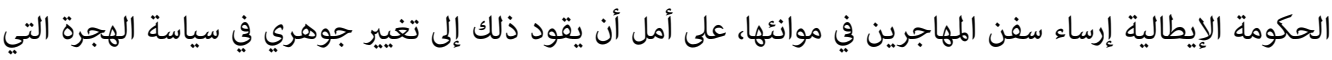

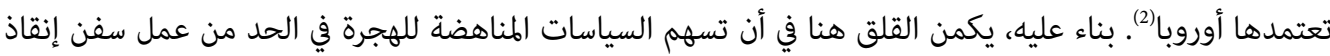

1

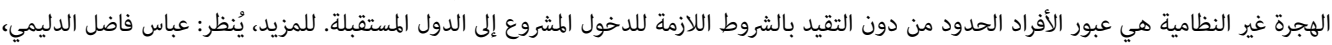

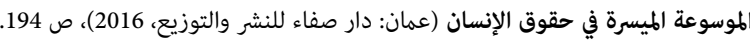


المهاجرين التي تتبع لجمعيات ومنظمات إنسانية(3)، كما أنها قد تدفع السفن التجارية مستقبلًا إلى تجاهل نداءات استغاثة المهاجرين في عرض البحر، والقيام بعمليات إنقاذ في ظل رفض الحكومات الأوروبية السماح بإنزال المهاجرين القادمين من سواحل دول الضفة الجنوبية للمتوسط، وعلى وجه التحديد السواحل الليبية (4). لقد مثّلت ليبيا نقطة الانطلاق الأساسية لمعظم تدفقات المهاجرين نحو الاتحاد الأوروبي؛ بسبب توافر العوامل التي تجعلها "نقطة تجمّع" لمئات المهاجرين القادمين من الشرق الأوسط ودول أفريقيا جنوب الصحراء، ينتقلون منها بقوارب "الموت" أو قوارب "الحظ" إلى أوروبا. فليبيا تعاني حالة انهيار شبه كامل لأجهزة الدولة ومؤسساتها المدنية

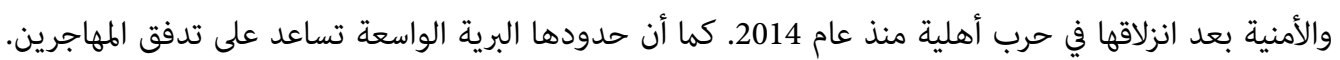
وفضلًا عن ذلك، نشطت شبكات الجريمة والاتجار بالبشر فيها ومارست انتهاكات خطيرة في مجال حقوق المهاجرين. تحاول الدراسة الإجابة عن السؤال الرئيس التالي: ما السياسات الأوروبية المشتركة نحو الهجرة غير النظامية انطلاقًا من السواحل الليبية؟ ونحاول أثناء الإجابة عن هذا السؤال البحث في كيفية تحول مسألة الهجرة من صلاحيات الدول الأعضاء إلى شأن أوروبي مشترك، ولا سيما أن تلك الدول كانت حتى وقت قريب تتعامل مع ظاهرة الهجرة من منظور أمني قومي، ولم تعطِ العمل

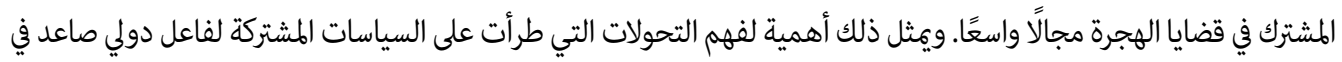

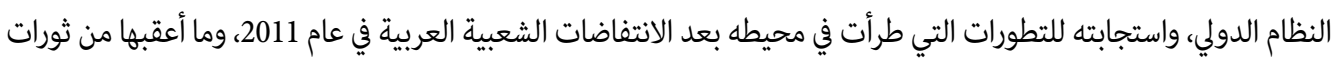
مضادة انهارت معها مؤسسات دول مثل سورية، وليبيا، واليمن. وقد فرض هذا الأمر على دول الاتحاد البحث عن نهج مشترك

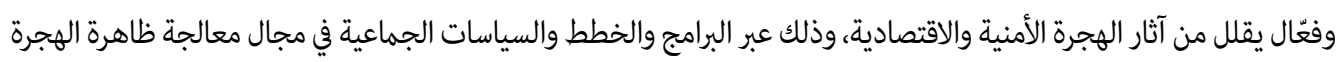
عمومًا، والهجرة غير النظامية خصوصًا. وسيتم التركيز في هذه الدراسة على حالة ليبيا، التي انتقلت من بلد مستقبل إلى بلد مصدّر

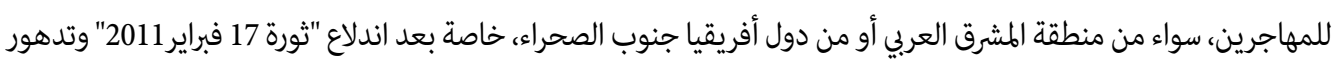
الأوضاع الأمنية والسياسية فيها. وفي هذا السياق، ترصد الدراسة استجابة الاتحاد الأوروبي لتدفقات المهاجرين القادمين من ليبيا. تعتمد الدراسة على مقاربة واقعية دفاعية(5) في فهم التوجه الأمني الجماعي للاتحاد الأوروبي في معالجته مسألة تدفقات المهاجرين انطلاقًا من السواحل الليبية. وقد شكلت نصوص الاتفاقيات والمعاهدات المؤسسة للاتحاد والقرارات والتوجيهات

3

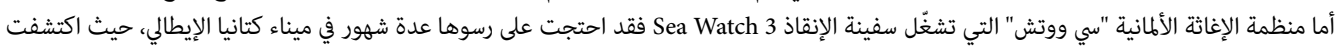

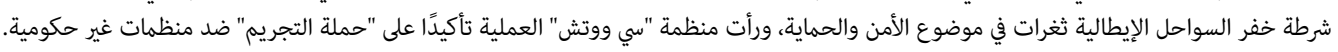

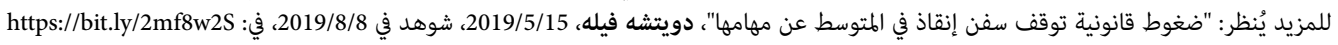

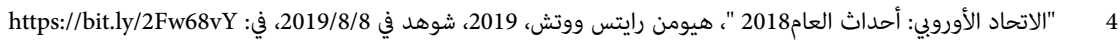
5

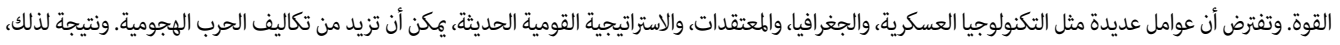

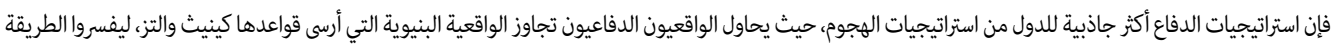

التي تتصرف بها الدول في النظام الدولي، من خلال دمجهم النظريات المتعلقة بالمستوى الداخلي مع تلكاتك المتتعلقة بمستوى النظام الدولي لتفسير الكيفية التي يعمل بها العات العالم.

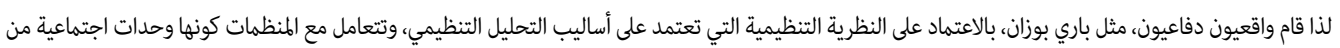

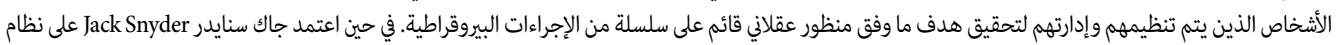

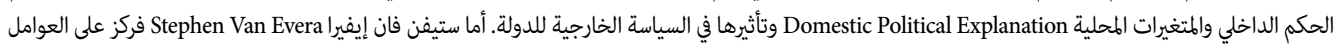

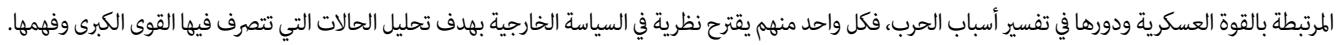

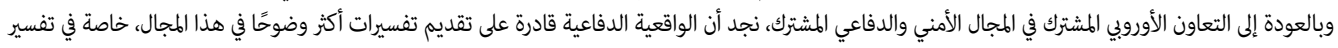

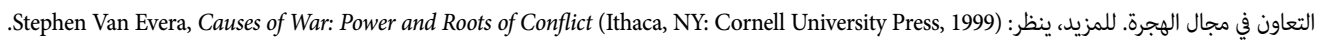


في مجال ضبط حركة الأفراد الأداة الأساسية لفهم محددات السياسات الأوروبية المشتركة؛ كونها تمثل برنامجَ عملٍ أوروبي

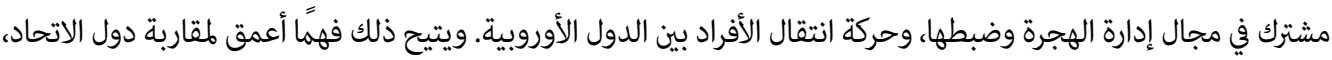
سواء أكانت الجنوبية (اليونان، وإيطاليا، وفرنسا، وإسبانيا) التي تشكّل سواحلها "استراحة مقاتل" للمهاجرين، أم الشمالية

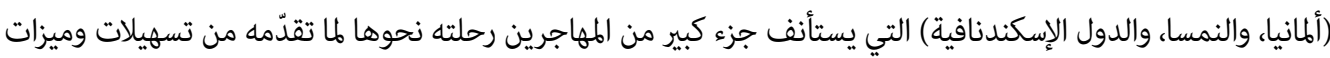

$$
\text { مقارنة بدول الجنوب الأوروبية. }
$$

تتضمن الدراسة ثلاثة محاور؛ يرصد الأول الدوافع والضرورات التي قادت دول الاتحاد الأوروبي إلى تبني سياسات

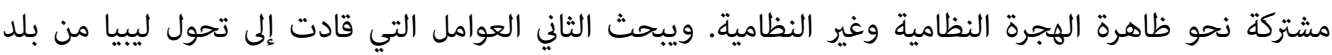

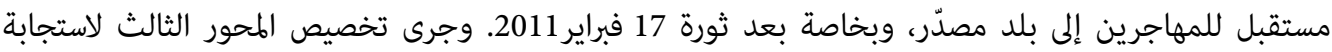

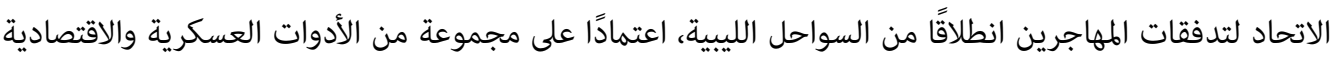
والسياسية التي اتبعها الاتحاد في محاولة للحد من الهجرة غير النظامية.

\section{أولًا: سياسة الهجرة وبرامجها في الاتحاد الأوروبي: الضرورات والدوافع}

أدت زيادة موجات المهاجرين نحو دول الاتحاد الأوروبي إلى وضع ظاهرة الهجرة على جدول أعمال الاجتماعات

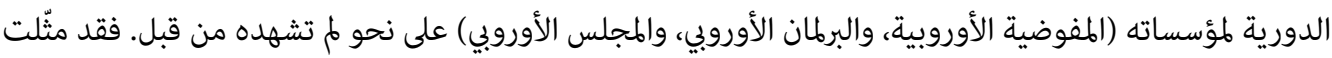
تلك الزيادة تحديًا كبيرًا استدعى إدارة مشتركة فعالة تقوم على تعزيز مراقبة الحدود وضبطها، ومكافحة شبكات التهات

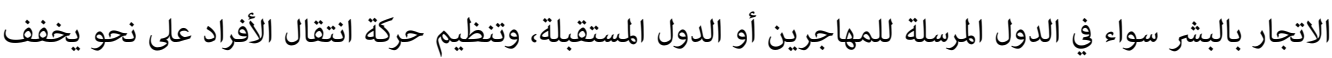
من الأعباء الاقتصادية والتهديدات الأمنية ومشكلات الاندماج الاجتماعي.

في المقابل، يعترف الاتحاد ضمنيًا بالدور المهم الذي تؤديه الهجرة في مسار التنمية الاقتصادية في ظل تراجع معدلات

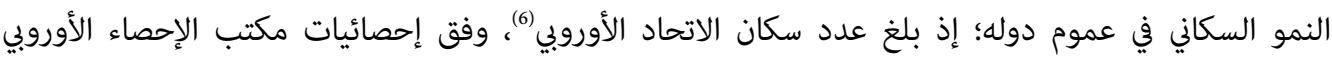
Eurostat

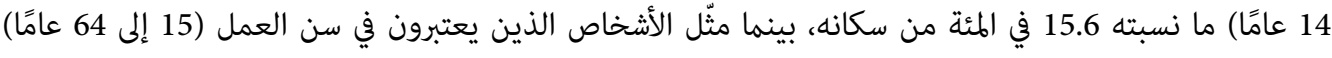

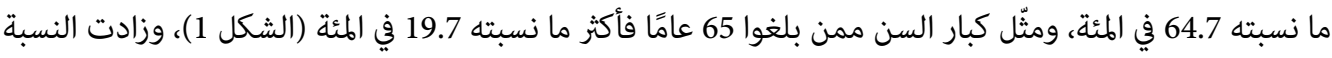

الأخيرة بنحو 0.3 في المئة مقارنة بعام 2017، و2.6 في المئة مقارنة بعام 2008 في جميع دول الاتحاد (7) مان.

كانت النسبة الأعلى من الشباب من إجمالي عدد السكان في دول الاتحاد في عام 2018 في أيرلندا (20.8 في المئة)، في حين سجّلت إيطاليا أدنى نسبة (13.4 في المئة)، وبلغت النسبة في ألمانيا (13.5 في المئة). أما فيما يتعلق بنسبة الأشخاص

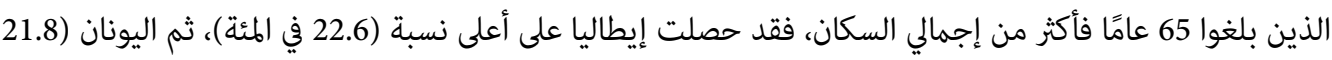

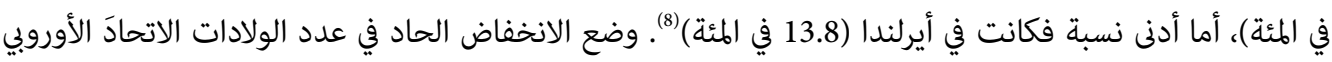
أمام تحدّي تعويض النقص المتزايد في عدد سكانه، ولقد مثّلت الهجرة على اختلاف طبيعتها، سواء أكانت نظامية

6 تشمل إحصائيات مكتب الإحصاء الأوروبي عدد سكان بريطانيا رغم خروجها من الاتحاد الأوروبي. 


\section{الشكل (1)}

توزيع النسب العمرية لسكان الاتحاد الأوروبي البالغ عددهم 512.4 مليون نسمة لعام 2018

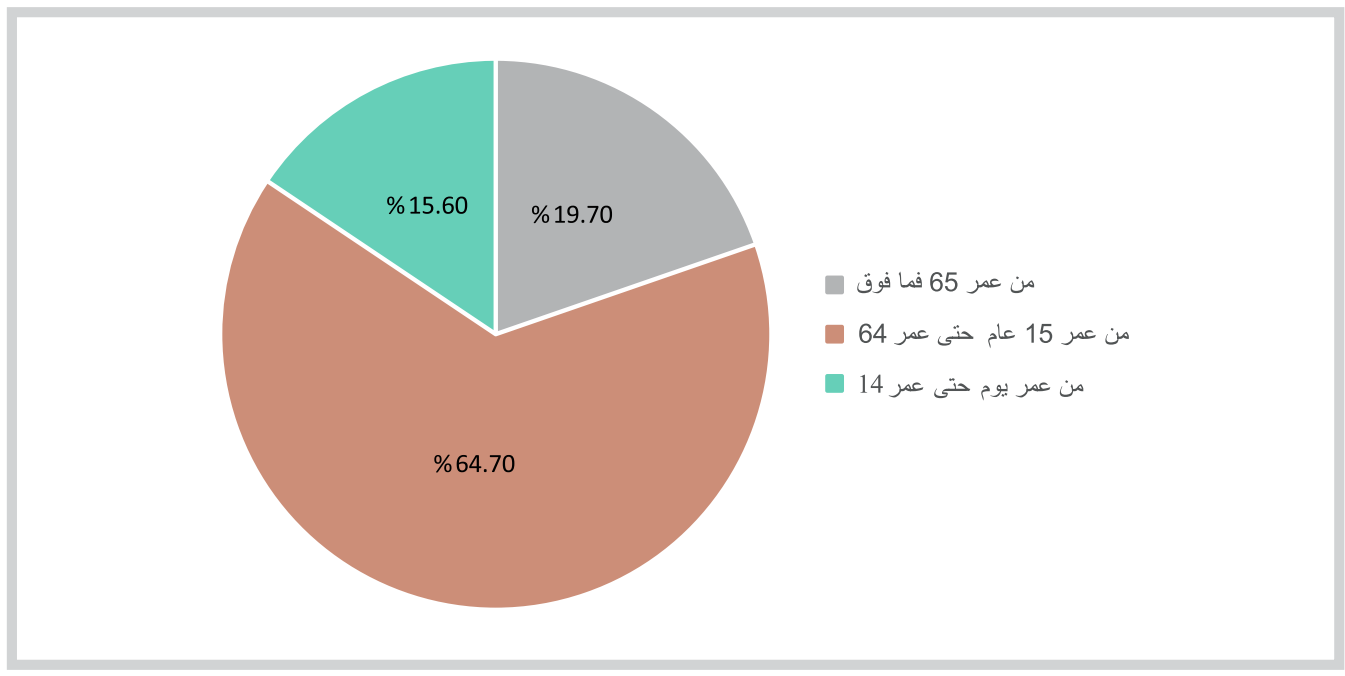

المصدر: من إعداد الباحث استنادًا إلى:

"Population Structure and Ageing," Eurostat Statistics Explained, July 2019, accessed on 9/9/2019, at: https://bit.ly/2FLNtw7

أم غير نظامية، مصدرًا مهمًا لتعويض التراجع الديموغرافي في دوله. في السياق ذاته، فرض ارتفاع تدفقات المهاجرين مجموعة من التحديات الاقتصادية والأمنية والاجتماعية، وعلى إثرها تعاملت دول الاتحاد مع ظاهرة الهجرة باعتبارها

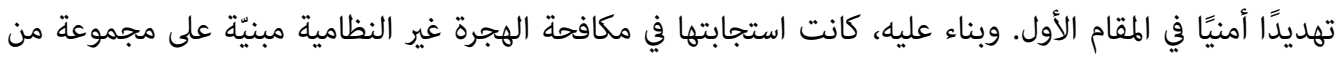
القواعد والتشريعات والتوجيهات التي طورتها في إطار التعاون والتكامل فيما بينها، والذي جسدته في سلسلة من الاتفاقيات المشتركة، إضافة إلى قوانينها وتشريعاتها القومية التي لا تزال تحتل المكانة الأبرز في إدارة الهجرة.

بالرجوع إلى الاتفاقية المؤسسة للجماعة الأوروبية European Community، التي وُقّعت في روما في 25 آذار/ مارس 1957، ودخلت حيز التنفيذ في 14 كانون الثاني/ يناير 1958 (9)، ثمة بند يربط مسألة الهجرة بعمل مؤسسات الجماعة؛ إذ خضعت مسائل تنظيم إصدار التأشيرات، ومنح حق اللجوء، وتنظيم الهجرة للتعاون بين

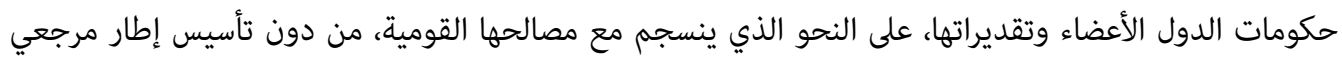

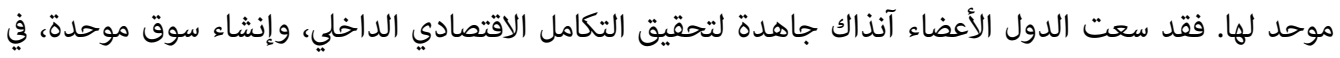
حين كانت الإثكاليات المرتبطة بالهجرة، سواء بين دول الجماعة نفسها أو من خارجها محدودة. وم تترافق حركة

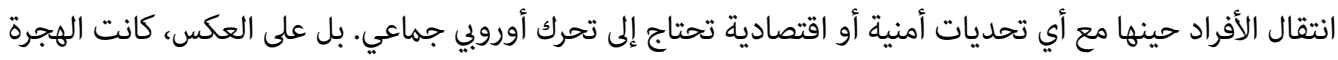

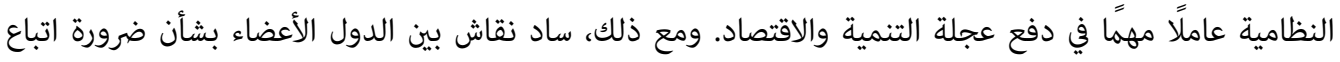
سياسة هجرة أوروبية مشتركة تسهم في تسريع إنشاء السوق الأوروبية الموحدة، وبخاصة أن حرية حركة حركة السلع والأفراد

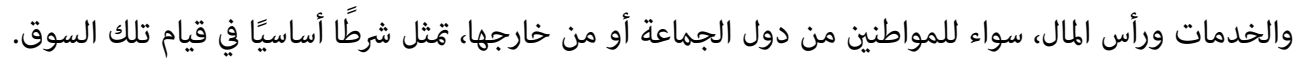


مل يستجب القانون الأوروبي الموحد، الذي دخل حيز التنفيذ في 1 توز/ يوليو 1987، للاحتياجات المتعلقة بتنظيم الهجرة على المستوى الأوروبي، على الرغم من طلب بعض دول الجماعة الأوروبية ضرورة العمل المنظم لإلغاء

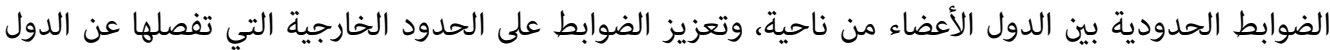

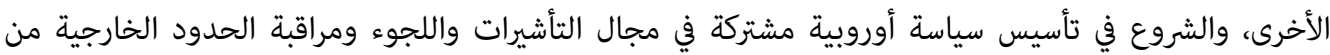

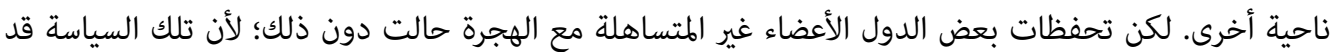
تجتذب أعدادًا كبيرة من المهاجرين الذين في إمكانهم الاستفادة من حرية التنقل بين دول الجماعة، متجاوزين في ذلك التشريعات القومية لكل دولة، كما تصبح الدولة مغلولة اليدين في سياسات التحكم والضبط التي تمارسها. لذا،

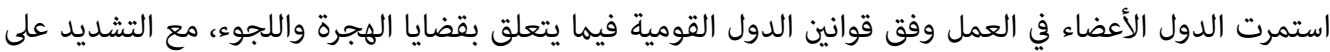
أهمية التعاون الحكومي فيما بينها في هذا المجال.

واصلت الدول الأعضاء في الجماعة العمل بالآلية ذاتها حتى اتفاقية ماستريخت Maastricht Treaty الموقعة

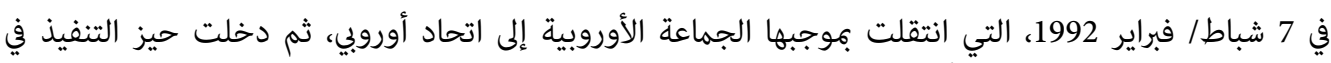

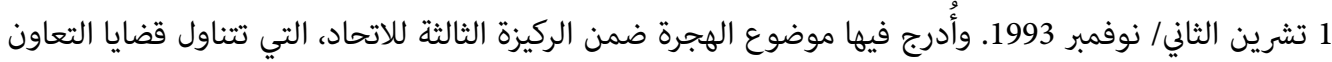
القضائي والشرطة في المسائل الجنائية، وتنص المعاهدة على التعاون بين الدول الأعضاء في القطاعات التي تعتبر قضايا ذات اهتمام مشترك، ومن بينها اللجوء والهجرة. كما دُمج التعاون الحكومي الدولي السابق في مجال الهجرة واللجوء في

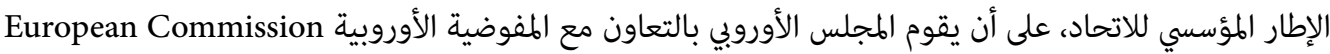

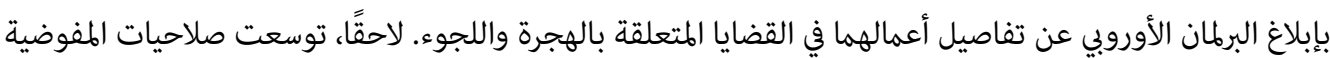
والمجلس في مجال وضع تشريعات في مجال الهجرة واللجوء، وذلك وفقًا لاتفاقية أمستردام

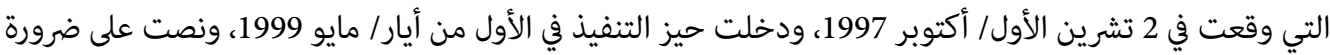
العمل على استحداث آليات مؤسساتية جماعية، واعتماد بعض التدابير المشتركة فيما يتعلق بالآتي: ه شروط الدخول والإقامة والقواعد التي تنظم إجراءات إصدار الدول الأعضاء تأشيرات طويلة الأجل، وتصاريح الإقامة، بما في ذلك الصادرة لغرض مُّ شمل الأسرة. ه الهجرة والإقامة غير النظاميتين، وبرامج إعادة غير المقيمين بطريقة قانونية إلى وطنهم. ه حقوق المقيم بطريقة نظامية في إحدى الدول الأعضاء. بناء على ذلك، صاغ المجلس الأوروبي خطة عمل بالتعاون مع المفوضية الأوروبية في الثالث من كانون الأول/ ديسمبر 1998 أطلق عليها اسم "خطة فيينا"، تشمل "أفضل السبل لتنفيذ أحكام معاهدة أمستردام في مجال الحرية والأمن والعدالة"(10.) وقد جاء في قسم سياسات الهجرة واللجوء ضرورة تطوير الأدوات الجماعية الأوروبية التي نصت عليها اتفاقية أمستردام في مكافحة الهجرة غير النظامية، بما يضمن حقوق المقيمين على نحو قانوني في الاتحاد، وكذلك

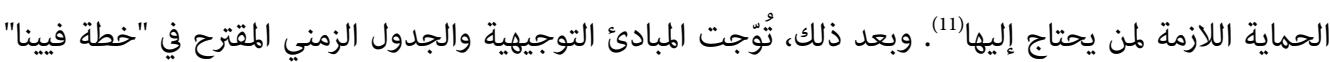

10 "Action Plan of the Council and the Commission on How Best to Implement the Provisions of the Treaty of Amsterdam on an Area of Freedom, Security and Justice - Text adopted by the Justice and Home Affairs Council of 3 December 1998," Eur-Lex, 23/1/1999, accessed on 5/8/2019, at: https://bit.ly/2kxm8Gv

11 Ibid. 
في اجتماع المجلس الأوروبي في مدينة تامبيري Tampere الفنلندية في الفترة 15-16 تشرين الأول/ أكتوبر 1999 بمجموعة استنتاجات بلورت الركيزة الأساسية الأولى لتأسيس سياسة هجرة أوروبية مشتركة، وهي (12):

ه بناء شراكات مع بلدان المصدر: يحتاج الاتحاد الأوروبي إلى نهج شامل إزاء الهجرة، من خلال معالجة القضايا السياسية وقضايا حقوق الإنسان والتنمية في بلدان ومناطق المصدر والعبور. ويتطلب هذا مكافحة الفقر، لهراء وتحسين الظروف المعيشية وفرص العمل، وحل النزاعات، وتعزيز الديمقراطية، واحترام حقوق الإنسان من خلال الشراكة مع بلدان المصدر والعبور. † التأسيس لنظام لجوء مشترك بين الدول الأعضاء: وافقت الدول على ضرورة العمل من أجل تأسيس نظام

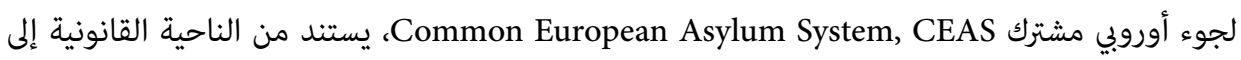
اتفاقية جنيف الموقعة في 12 آب/ أغسطس 1949 ، ووضع معايير مشتركة لإجراءات اللجوء السياسي والإنساني، وتقريب القواعد المتعلقة بالاعتراف بوضع اللاجئ بين الدول الأعضاء في الاتحاد على المدى الطويل. ه آليات وتدابير محددة تتعلق بالمعاملات القانونية العادلة لمواطني الدول غير الأعضاء في الاتحاد: تهدف برامج الاندماج إلى توضيح حقوق هؤلاء وواجباتهم، وعدم التمييز في الحياة الاقتصادية والاجتماعية

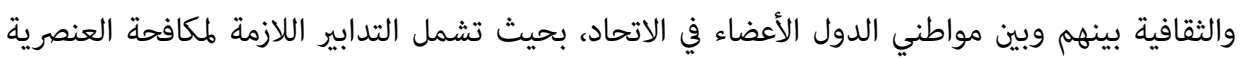
وكراهية الأجانب.

ه الإدارة الفعالة والمنسقة لتدفقات المهاجرين: الحاجة إلى إدارة تدفقات المهاجرين من خلال التعاون الوثيق

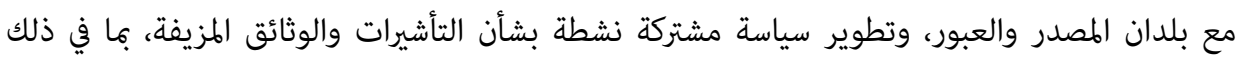

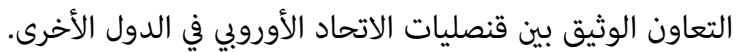

بناء عليه، بدأت مرحلة جديدة في السياسات الأوروبية المشتركة نحو الهجرة خلال الفترة 1999-2014، حيث تقوم مؤسسات الاتحاد بتقييم دوري "كل خمس سنوات" للسياسات المتبعة وصياغة محددات وتوجهات جديدة

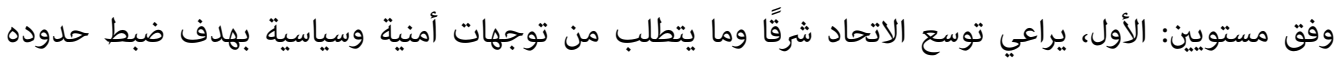

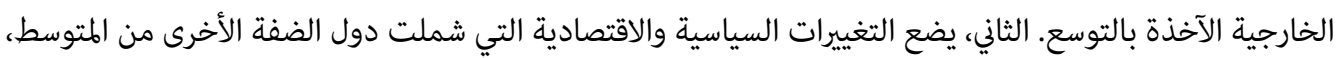
وضرورات التحرك المشترك للحد من آثارها.

\section{1. المرحلة الخمسية الأوله (1999-2004)}

ركزت النقاشات بين ممثلي الدول الأعضاء ضمن مؤسسات الاتحاد في هذه المرحلة، التي امتدت من اجتماع تامبيري في عام 1999 حتى أيار/ مايو 2004، على ضرورة اعتماد آليات وتدابير تحد من ظاهرة الهجرة غير النظامية، وتهدف

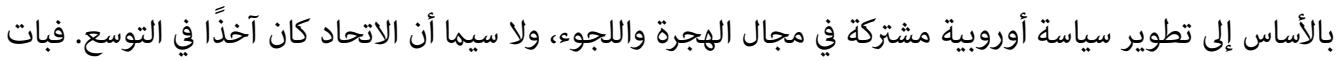
من الضروري العمل على ابتكار آليات مشتركة تسهم في حل القضايا المتعلقة بحركة الأفراد وتنقلهم. وبناءً على هذه مهاه

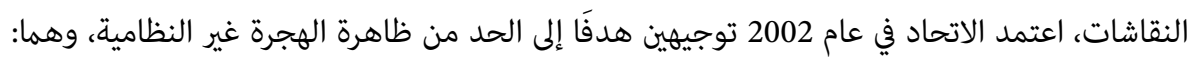


هـ التوجيه الصادر عن المجلس الأوروبي في 28 تشرين الثاني/ نوفمبر 2002(13): يعالج مسألة الدخول غير القانوني للأفراد وعبورهم وإقامتهم في إحدى دول الاتحاد. وينص على أن تقوم كل دولة عضو بفرض عقوبات على أي شخص يساعد عمدًا مواطنًا من دولة ثالثة على الدخول إلى الاتحاد أو عبوره أو الإقامة

$$
\text { فيه بصورة غير قانونية. }
$$

هـ القرار الإطاري رقم 946/2002 الصادر عن المجلس الأوروبي في 28 تشرين الثاني/ نوفمبر 2002(14): يرمي إلى تعزيز التعاون الجنائي بين الدول الأعضاء بهدف الحد من عمليات تيسير الدخول غير القانوني للأفراد والعبور والإقامة. كما يحدد القواعد المطبقة على الدول الأعضاء فيما يتعلق بالعقوبات ومسؤولية الأشخاص

$$
\text { الطبيعيين والاعتباريين والولاية القضائية للجرائم المتعلقة بتسهيل الهجرة غير النظامية. }
$$

وصدر توجيه عن المجلس في نيسان/ أبريل 2004 حول مسألة الاتجار بالبشر المرتبطة بالهجرة غير القانونية، ينص على منح تصريح إقامة مدةً محدودة لا تقل عن ستة أشهر لضحايا الاتجار بالبشر. وأعطى التوجيه الدول الأعضاء في الاتحاد الحق في توسيع نطاقه لمواطني الدول غير الأعضاء الذين وقعوا ضحايا عمليات الهجرة غير النظامية، وذلك بالكشف عن الأشخاص القائين على شبكات الاتجار بالبشر وتسهيل الهجرة، مع ضمان حمايتهم من أي اعتداء أو

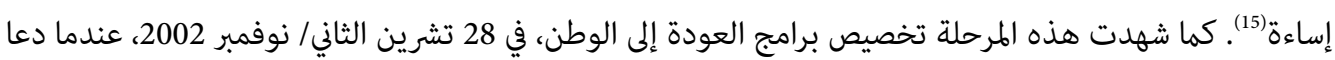
المجلس إلى تطوير التعاون في مجال سياسات العودة إلى الوطن من خلال التنسيق بين الدول الأعضاء، وبرامج العودة الخاصة بكل بلد، وتكثيف التنسيق والتعاون مع بلدان المصدر، بما في ذلك عمليات إعادة المهاجرين غير النظاميين عن طريق الجو. فقد أقر المجلس التوجيه رقم 573/2004(16) بشأن تنظيم رحلات جوية مشتركة لنقل رعايا الدول غير الأعضاء في الاتحاد الموجودين بصورة غير قانونية في أراضي دولتين أو أكثر من الدول الأعضاء. يهدف القرار، الذي تم تبنّيه بناءً على المبادرة الإيطالية، إلى تنسيق عمليات الترحيل المشتركة جوًا، وتحديد المهمات المحددة للسلطات المعنية بعمليات الترحيل.

كما قامت الدول الأعضاء بإنشاء شبكة من ضباط الاتصال في مجال الهجرة في عام 2004، وفقًا للائحة رقم2004/377 (17)؛ بهدف تسهيل تبادل المعلومات ذات الصلة بمكافحة الهجرة غير النظامية وتسهيل إدارة تدفقات الهجرة على نحو أكثر فاعلية مع الدول غير الأعضاء في الاتحاد. وينتشر حاليًا نحو 500 ضابط اتصال في أكثر من 100 دولة. وقد اعتمد

13 "Council Directive 2002/90/EC of 28 November 2002 Defining the Facilitation of Unauthorized Entry, Transit and Residence," Eur-Lex, 5/12/2002, accessed on 1/8/2019, at: https://bit.ly/2lQ1L7q

14 "Council Framework Decision of 28 November 2002 on the Strengthening of the Penal Framework to Prevent the Facilitation of Unauthorised Entry, Transit and Residence," Eur-Lex, 5/12/2002, accessed on 1/8/2019,at: https://bit.ly/2kImdqD

15 "Council Directive 2004/81/EC of 29 April 2004 on the Residence Permit Issued to Third-country Nationals who are Victims of Trafficking in Human Beings or who have been the Subject of an Action to Facilitate Illegal Immigration, who Cooperate with the Competent Authorities," Eur-Lex, 29/4/2004, accessed on 2/8/2019, at:https://bit.ly/2lKkJfW

16 "Council Decisionon the Organization of Joint Flights for Removals from the Territory of Two or more Member States, of Thirdcountry Nationals who are Subjects of Individual Removal Orders," Eur-Lex, 29/4/2004, accessed on 6/9/2019, at: https://bit.ly/2kks8SC

17 "Council Regulation (EC) No 377/2004 of 19 February 2004 on the Creation of an Immigration Liaison Officers Network," Eur-Lex, 2/3/2004, accessed on 7/9/2019, at: https://bit.ly/2mozmpn 
المجلس الأوروبي مجموعة من القواعد الجديدة بهدف تعزيز التنسيق بين أعضاء الشبكة لإدارة الهجرة غير النظامية والحد منها، والعمل على تسهيل عودة المهاجرين إلى أوطانهم (18).

صدّق الاتحاد الأوروبي في 8 شباط / فبراير 2003 "نظام دبلن 2" للتعامل مع طلبات اللجوء في الاتحاد، وهو بمنزلة نسخة

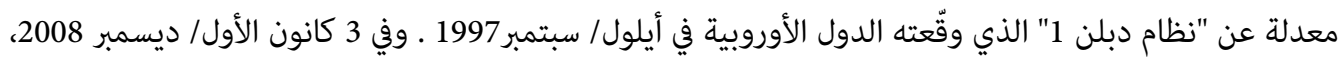
اقترحت المفوضية الأوروبية إدخال تعديلات أخرى على "نظام دبلن"، أقرتها الدول الأعضاء في حزيران/ يونيو 2013،

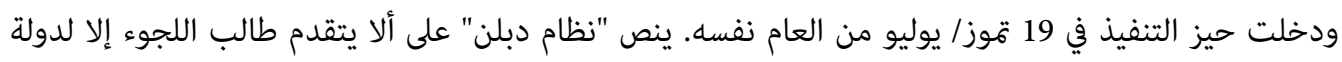
واحدة فقط من دول الاتحاد. وقد ساهم إنشاء قاعدة بيانات للبصمات EURODAC على مستوى الاتحاد الأوروبي في معرفة كل من يدخل دولةً عضوًا بطريقة غير نظامية؛ إذ تحتفظ قاعدة البيانات ببصمة طالب اللجوء ولا تزول

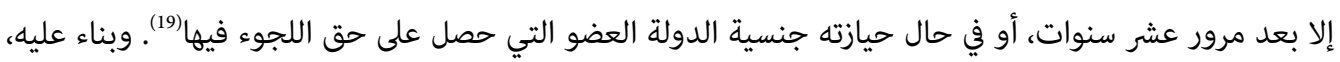

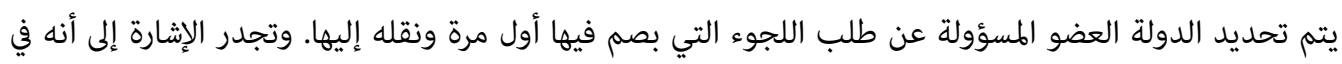

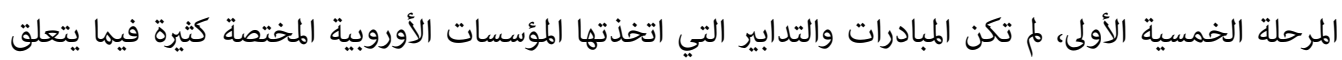

بالهجرة النظامية؛ فقد اعتمد الاتحاد توجيهين في هذا الصدد، هما:

ه التوجيه بشأن الحق في مُّ شمل الأسرة: اعتمد المجلس التوجيه رقم 86/2003 بشأن الحق في ملّ شمل الأسرة

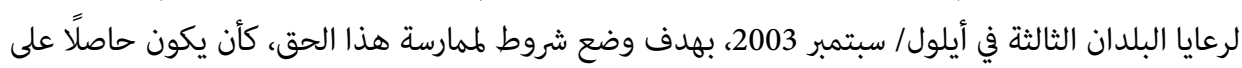

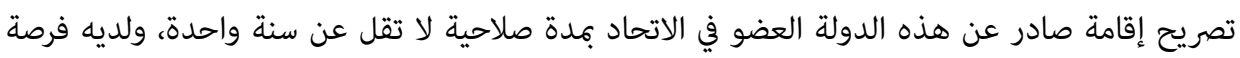
قوية للحصول على حق الإقامة هناك إقامة دائة (إقامة عمل، دراسة ... إلخ). كما تجدر الإشارة إلى أنه قد يتم رفض دخول فرد من العائلة وإقامته لأسباب تتعلق بالنظام العام والأمن الداخلي والصحة العامة العهام. وللدول الأعضاء الحق في اشتراط تدابير إضافية، كتلك المنصوص عليها في القانون فيما يتعلق بالاندماج (20). ه التوجيه بشأن منح الإقامة الدائةة: اعتمد المجلس التوجيه رقم 109/2003 في 25 تشرين الثاني/ نوفمبر

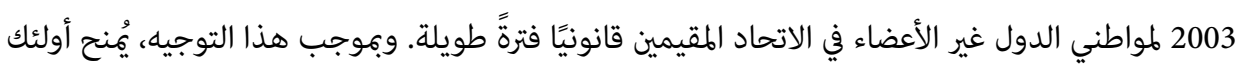
الذين أقاموا على نحو قانوني ومستمر مدة خمس سنوات في إقليم دولة عضو سلسلة من الحقوق، منها الحصول على الإقامة الدائمة. ويجب أن يثبت مواطن الدولة الثالثة أنه وأسرته لديهما موارد مستقرة وكافية لتوفير احتياجاتهما الخاصة من دون اللجوء إلى نظام المساعدة الاجتماعية في الدولة العضو والتأمين ضد ضد الدي

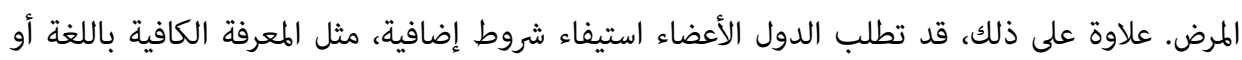
الإقامة الكافية(21). وصدر عن المجلس توجيه آخر مهم خلال هذه المرحلة، وهو التوجيه رقم

18 "Immigration Liaison Officers: Council Adopts New Rules to Improve Coordination," European Council, 14/6/2019, accessed on 2/8/2019, at: https://bit.ly/2kJXORT

19 "Regulation (EU) No. 604/2013 of the European Parliament and of the Council of 26 June 2013 Establishing the Criteria and Mechanisms for Determining the Member State Responsible for Examining an Application forInternational Protection Lodged in one of the Member States by a Third-country National or a Stateless Person(recast)," Eur-Lex, 29/6/2013, accessed on 16/9/2019, at: https://bit.ly/2mfa3X6

20 "Council Directive 2003/86/EC of 22 September 2003 on the Right to Family Reunification," Eur-Lex, 3/10/2003, accessed on 12/9/2019, at: https://bit.ly/2mjnnt8

21 "Council Directive 2003/109/EC of 25 November 2003 Concerning the Status of Third-country Nationals who are Long-term Residents," Eur-Lex, 23/1/2004, accessed on 12/9/2019, at: https://bit.ly/2mmT5FW 
المتعلق بشروط قبول رعايا البلدان غير الأعضاء في الاتحاد للدراسة وتبادل الطلاب والتدريب الداخلي غير

$$
\text { المدفوع الأجر أو التطوع (22). }
$$

قيزت المرحلة الخمسية الأولى بقدر كبير من اهتمام دول الاتحاد بإدارة ظاهرة الهجرة غير النظامية. واتخذت

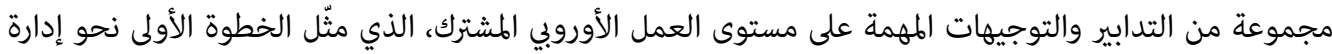

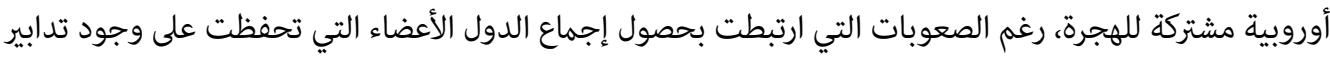
وتوجيهات تشريعية أوروبية تحد من التشريعات القومية في مجال إدارة تدفقات المهاجرين عبر حدودها والتحكم فيها. فضلًا عن ذلك، حدثت تغييرات خلال تلك المرحلة الخمسية الأولى بدءًا من هجمات 11 سبتمبر 2001 في الولايات المتحدة، واحتلال كل من أفغانستان والعراق، وتفجيرات مدريد في عام 2004 ولندن في عات فام في مضامين سياسات الاتحاد الأوروبي بشأن الهجرة.

\section{2. المرحلة الخمسية الثانية (2005-2010): برنامج لاهامي}

صاغت المفوضية الأوروبية برنامجًا جديدًا في بداية المرحلة الخمسية الثانية بهدف تطوير العمل الأوروبي المشترك

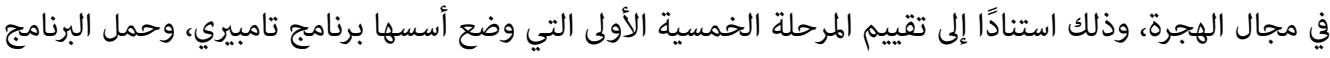

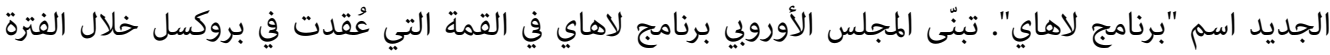

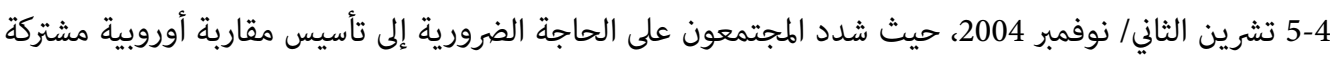

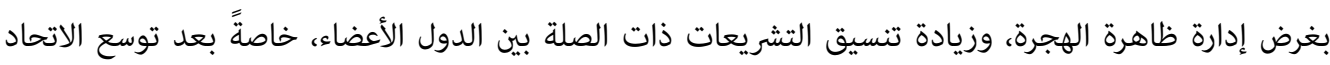

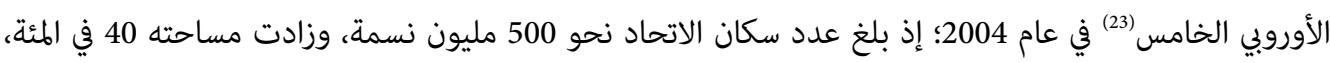

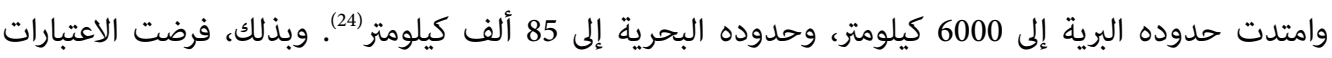
الجيوسياسية على دول الاتحاد العمل الجاد في سبيل وضع مجموعة من المشاريع والبرامج المشتركة لضمان وان وتأمين حدوده الخارجية من التهديدات، وعلى رأسها الهجرة غير القانونية.

في هذا السياق، دعا المجلس المفوضية إلى صياغة خطة عمل لتحقيق الأهداف والأولويات الواردة في برنامج لاهاي، وتحويلها إلى إجراءات ملموسة وفق جدول زمني محدد. لبّت المفوضية طلب المجلس الأوروبي، وحددت المباديادئ

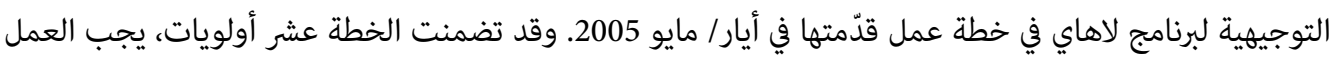

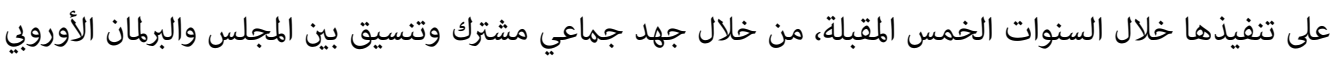
والمفوضية في إطار شراكة قوية وفعالة في مجال الحرية والأمن والعدالة. ويكن تلخيص هذه هذه الأولويات على النحون

22 "Council Directive 2004/114/ECof 13 December 2004 on the Conditions of Admission of Third-country Nationals for the Purposes of Studies, Pupil Exchange, Unremunerated Training or Voluntary Service," Eur-Lex, 23/12/2004, accessed on 13/9/2019, at: https://bit.ly/2kuhEAn

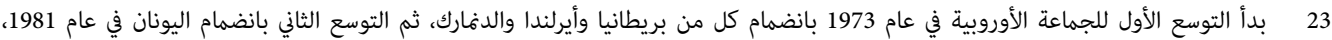

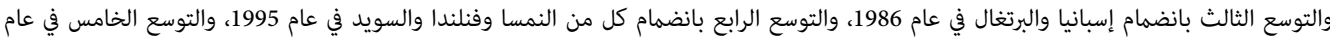

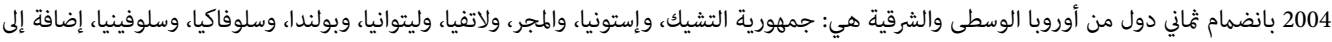

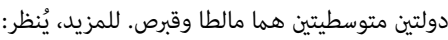
"From 6 to 28 Members," European Commission, accessed on 9/9/2019, at: https://bit.ly/2mQEeyU 24 للأبحاث ودراسة السياسات، 2014)، ص 213. 
التالي: 1. المواطنة والحقوق الأساسية، 2. محاربة الإرهاب، 3. تأسيس نظام لجوء مشترك، 4. إدارة الهجرة النظامية وغير النظامية، 5. التركيز على الأثر الإيجابي للهجرة في مجتمعات واقتصاد الدول الأعضاء، 6. ضبط الحدود الداخلية

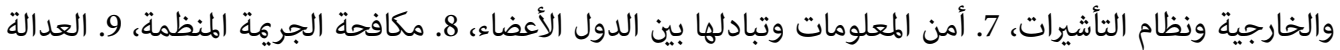
المدنية والجنائية، 10. الحرية والأمن والعدالة واقتسام المسؤولية والتعاون بين الدول (25).

ركزت الدول الأعضاء في المرحلة الخمسية الثانية على ضرورة التعاون مع بلدان المصدر والعبور في مجال مكافحة الهجرة غير النظامية. وقد شدد المجلس الأوروبي على الحاجة إلى تكثيف التعاون وبناء القدرات التي تضمن أمن فرداء الحدود الجنوبية والشرقية للاتحاد، وقكين بلدان العبور من إدارة الهجرة على نحو يوفر الحماية الكافية للاجئين. كما اعتمد المجلس الأوروبي توجيهًا، في 16 كانون الأول/ ديسمبر 2008، ينظم عمليات العودة لمواطني الدول غير الأعضاء في الاتحاد الأوروبي وامتثالهم طواعية لعمليات العودة، وذلك بناء على مقترح تقدمت بهاء به المفوضية في عام 2005، ينص على حق الدولة العضو إصدار قرار بإعادة أي مواطن دولة غير عضو في الاتحاد مقيم إقامة غير قانوانونية

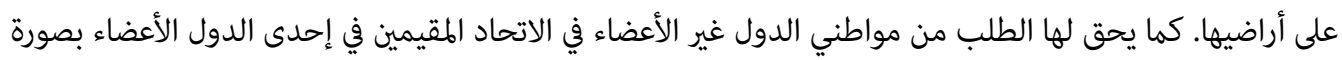

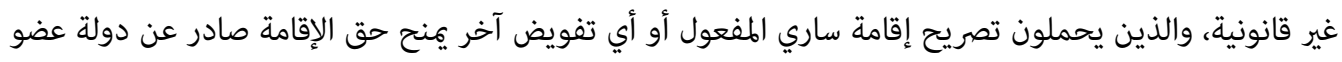
أخرى، العودة إلى إقليم تلك الدولة العضو الأخرى على الفور (26).

وتضمّن التوجيه مبدأ الإعادة الطوعية للوطن لمواطني الدول غير الأعضاء في الاتحاد الذين يقيمون بصورة غير

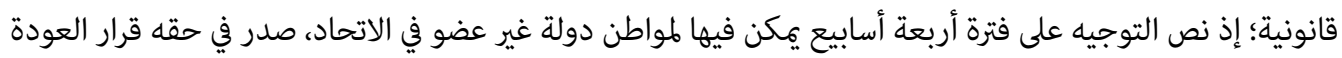

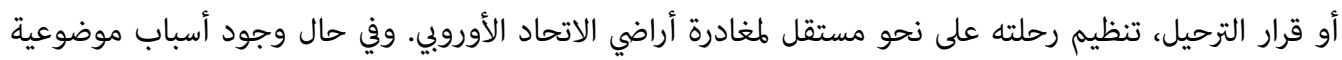

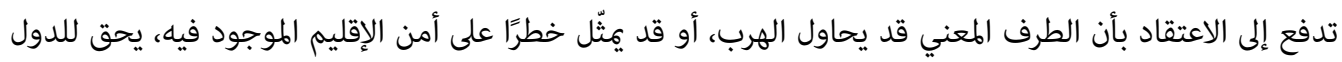

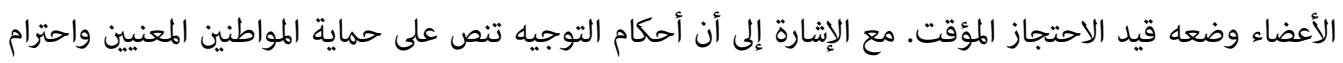

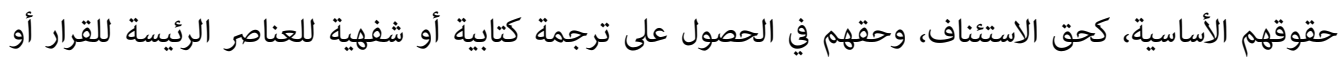
الحكم الصادر في حقهم.

في المقابل، اتخذ الاتحاد خطوات أخرى في مجال الهجرة النظامية، منها التوجيه الصادر في 12 تشرين الأول/ أكتوبر

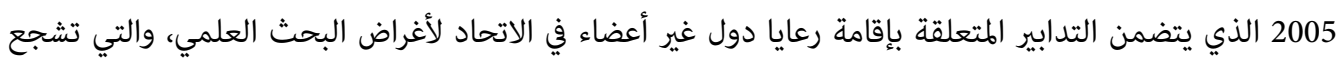

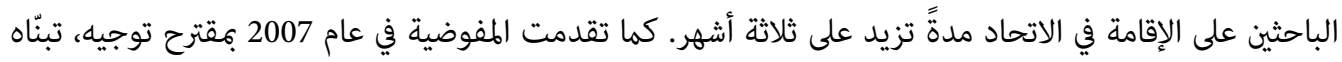

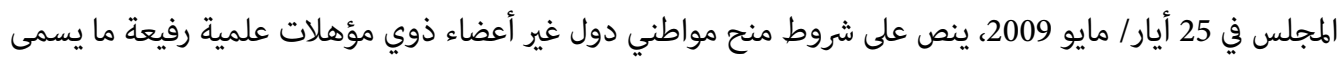

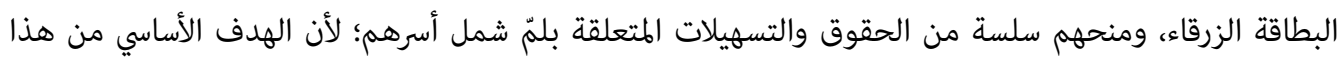
التوجيه هو جذب المهاجرين المؤهلين مهنيًا (27).

25 "Communication from the Commission to the Council and the European Parliament - The Hague Programme: Ten Priorities for the Next Five Years The Partnership for European renewal in the field of Freedom, Security and Justice," Eur-Lex, 10/5/2005, accessed on 10/9/2019, at: https://bit.ly/21ZnMRq

26 "Directive 2008/115/EC of the European Parliament and of the Council of 16 December 2008 on Common Standards and Procedures in Member States for Returning Illegally Staying Third-country Nationals," Eur-Lex, 24/12/2008, accessed 3/9/2019, at: https://bit.ly/2m2iuEK

27 "Council Directive 2009/50/EC of 25 May 2009 on the Conditions of Entry and Residence of Third-Country Nationals for the Purposes of Highly Qualified Employment," Eur-Lex, 18/6/2009, accessed on 4/9/2019, at:https://bit.ly/2kWxOCK 
أما تبادل المعلومات بهدف تنسيق سياسات الهجرة على مستوى الدول القومية ومؤسسات الاتحاد، فقد اعتمد المجلس في عام 2007 اللائحة رقم 2007/862 التي تحدد قواعد مشتركة لجمع المعلومات المتعلقة بمواطني الدول

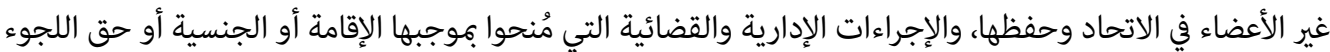

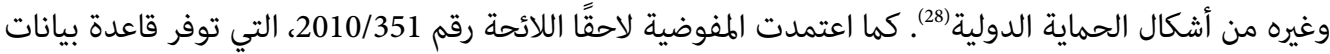

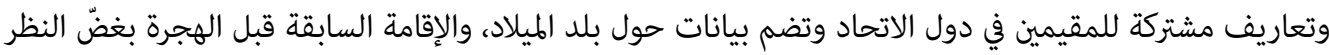
عن جنسيته، وبلد الإقامة الحالي (29.). وتم إنشاء شبكة الهجرة الأوروبية European Migration Network, EMN، بموجب القرار رقم 381/2008، لتوفير معلومات محدثة وموضوعية وموثوقة تسمح بإجراء المقارنات حول الهجرة لمؤسسات الاتحاد الأوروبي وسلطات الدول الأعضاء ومؤسسات شبكة الهجرة الأوروبية؛ من أجل دعم عملية صنو صنع القرار في الاتحاد الأوروبي في مجالات الهجرة واللجوء (30).

\section{3. المرحلة الخمسية الثالثة (2010-2014): برنامج ستوكهولم}

أدى الإخفاق في وضع دستور للاتحاد الأوروبي في عام 2005 إلى أن تصوغ الدول الأعضاء اتفاقية جديدة هي

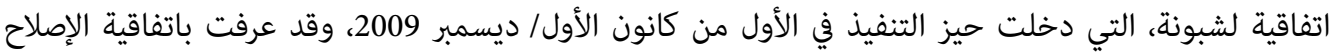
Reform Treaty

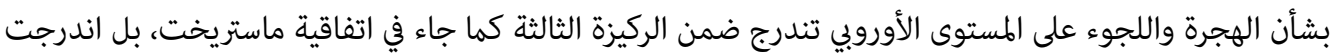
في الباب الخامس من اتفاقية لشبونة تحت عنوان "مجال الحرية والأمن والعدالة" مع تطبيق متمايز لمواد هذا الباب الباء في كل من بريطانيا وأيرلندا وفق بروتوكولات محددة ملحقة بالاتفاقية (البروتوكول رقم 21 والبروتوكول رقم 22). ومع انتهاء المرحلة الخمسية الثانية "برنامج لاهاي"، اعتمد المجلس الأوروبي في كانون الأول/ ديسمبر 2009 برنامجًا جديدًا "برنامج ستوكهوم" Stockholm Programme (2010-2014) وفقًا للتعديلات التي أدخلتها اتفاقية لشبونة. وقد أكدت الدول الأعضاء في هذا البرنامج ضرورة أن تكون سياسة الهجرة جزءًا لا يتجزأ من السياسة الخارجية

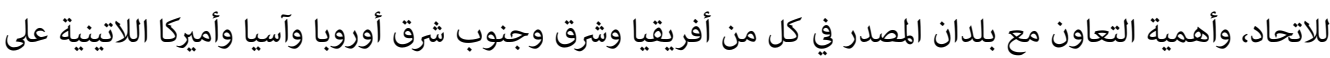

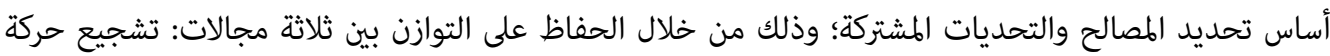

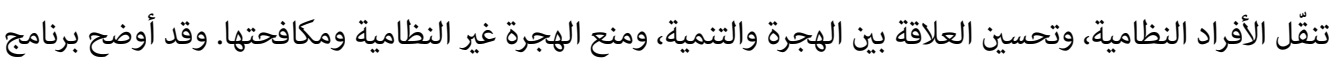

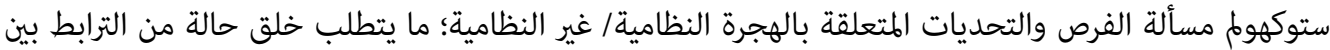

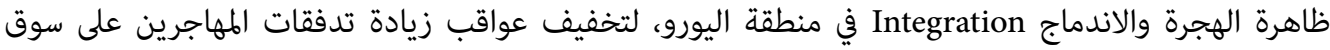

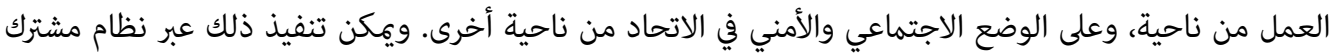

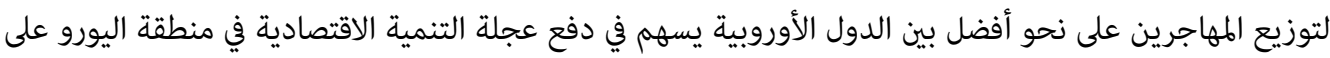

28 "Regulation (EC) No 862/2007 of the European Parliament and of the Council of 11 July 2007 on Community Statistics on Migration and International Protection and Repealing Council Regulation (EEC) No 311/76 on the Compilation of Statistics on Foreign Workers," Eur-Lex, 31/7/2007, accessed on 2/8/2019, at: https://bit.ly/2kt4bJ3

29 "Commission Regulation (EU) No 351/2010 of 23 April 2010 Implementing Regulation (EC) No 862/2007 of the European Parliament and of the Council on Community Statistics on Migration and International Protection as Regards the Definitions of the Categories of the Groups of Country of Birth, Groups of Country of Previous Usual Residence, Groups of Country of Next Usual Residence and Groups of Citizenship," Eur-Lex, 12/9/2019, accessed on 2/8/2019, at: https://bit.ly/2m74DNi

30 "Council Decision of 14 May 2008 establishing a European Migration Network," Eur-Lex, 21/5/2008, accessed on 12/9/2019, at: https://bit.ly/2m7Gbvh 
المدى الطويل، في ظل التحديات الديموغرافية التي تواجه دول الاتحاد، كتراجع عدد السكان والتشيخ السكاني وزيادة

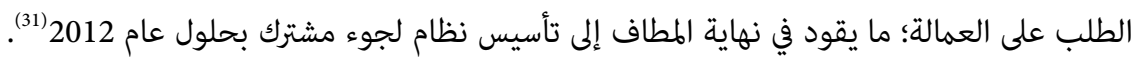
مثّلت الانتفاضات الشعبية في المنطقة العربية عام 2011 تحولًا مفاجثًا، دفع قادة الاتحاد الأوروبي إلى إعادة النظر في كل سياسات الهجرة وتقيمها، خاصة مع ازدياد تدفقات المهاجرين عبر شواطئ دول شمال أفريقيا وعلى وجه

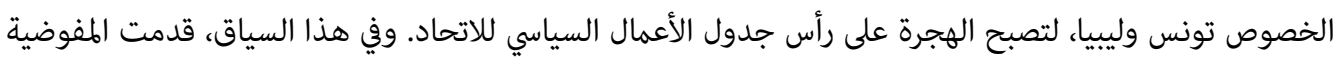
الأوروبية مجموعة من المقترحات المتعلقة بالهجرة وحركة الأفراد في بلاغها الصادر في أيار/ مايو

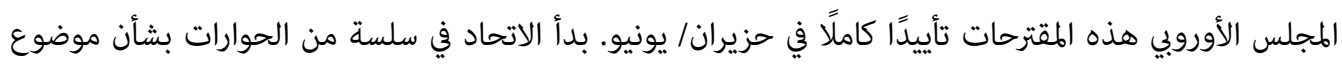

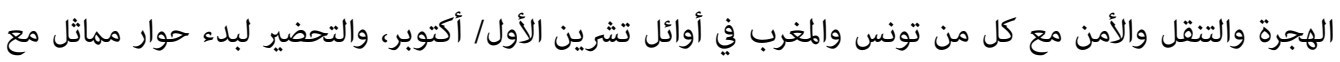
مصر وليبيا ريثما تستقر الأمور فيهما، بهدف مناقشة جميع جوانب التعاون المحتمل في إدارة تدفقات الهجرة بها

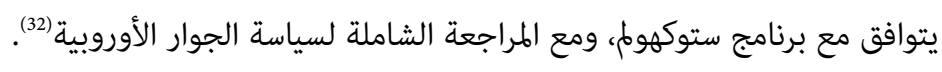
خصصت المفوضية موارد مالية لإدارة حالة الطوارئ الإنسانية الناتجة من تدفقات المهاجرين واللاجئين في البلدان

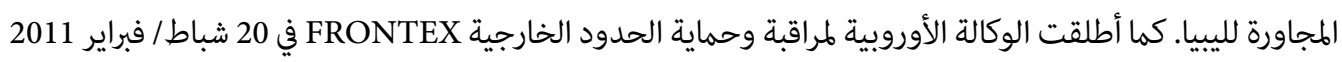
العملية المشتركة EPN Hermes Extension، لمساعدة السلطات الإيطالية في إدارة تدفق المهاجرين من شمال أفريقيا، الذين وصل معظمهم إلى جزيرة لامبيدوسا Lampedusa

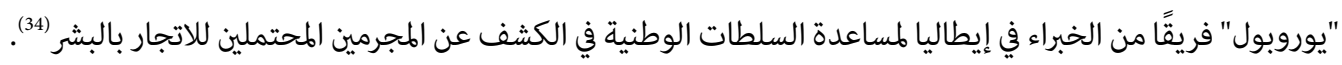

واستكمالًا كاا قامت به المفوضية في مجال إدارة الهجرة، فقد تبنّت في 8 تشرين الثاني/ نوفمبر 2011 المقاربة العالمية الجديدة للهجرة والتنقل (35)، التي اقترحت بموجبها تعزيز التضامن داخل الاتحاد الأوروبي في مجال إدارة الهجرة واللجوء

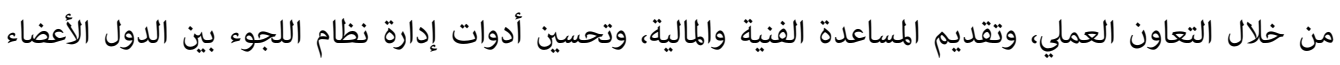
من ناحية. ومن ناحية أخرى ربط الاتحاد بدول المصدر والعبور باتفاقيات شراكة في مجال حركة الأفراد وتنقّلهم من ناحية. ومن ناحئة Mobility Partnership

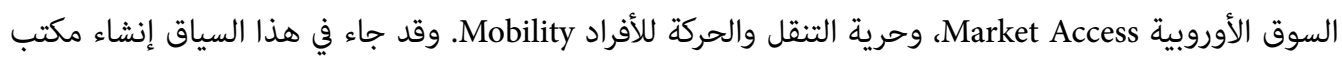
دعم اللجوء الأوروبي European Asylum Support Office, EASO، الذي من شأنه تعزيز التعاون العملي في مجال

31 "The Stockholm Programme - An open and secure Europe serving and protecting the citizens," Council ofthe European Union, 1/12/2009, accessed on 10/9/2019, at: https://bit.ly/2mprTX3

32 "Communication from the Commission to the European Parliament, the Council, the European Economic and Social Committee and the Committee of the Regions: A Dialogue for Migration, Mobility and Security with the Southern Mediterranean Countries," Eur-Lex, 24/5/2011, accessed on 14/9/2019, at: https://bit.ly/2kYx7sC

33 جزيرة 33

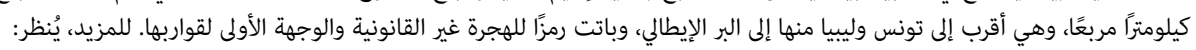
Micol Sarfatti, "La grazia di Lampedusa: piccola, lontana e coraggiosa," Corriere della Sera, 28/8/2017, accessed on 9/9/2019, at: https://goo.gl/afCLgP

34 "The European Commission's Response to the Migratory Flows from North Africa," European Commission, 8/4/2011, accessed on 10/9/2019, at: https://bit.ly/2mvu9MF

35 "Communication from the Commission to the European Parliament, the Council, the European Economic and Social Committee and the Committee of the Regions: The Global Approach to Migration and Mobility,"Eur-Lex,18/11/2011, accessed on 9/9/2019, at: https://bit.ly/2mvWZMV 
اللجوء، ولا سيما أن التجربة الأولية لنظام اللجوء المشترك CEAS أظهرت ضرورة تعميق التنسيق في مجال التشريعات لخلق الثقة بين جميع الدول الأعضاء بأنها تؤدي المهمات نفسها بطريقة مماثلة وبنتائج إيجابية في مجال اللجوء (36).

\section{ثانيًا: ليبيا والهجرة غير النظامية}

مثّلت ليبيا قبل ثورة 17 فبراير 2011 وجهة رئيسة للعمالة الوافدة من دول عربية وأفريقية. وتعود أولى تدفقات العمالة المهاجرة إلى سبعينيات القرن الماضي نتيجة التطور السريع الذي شهدته البلاد التي قملك ثروات نفطية كبيرة، وكانت بحاجة ملحّة إلى العمالة الأجنبية في مشاريع البنية التحتية. وقد شكلت مصر وتونس المصدر الأساسي للعمالة

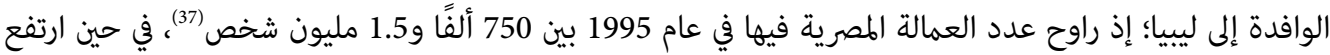
عدد المهاجرين من دول أفريقيا جنوب الصحراء من 40 ألف شخص في عام 1995 إلى 1.5 مليون في عام 2000 وفق إلق إحصائيات رسمية ليبية (38) في السياق ذاته، شجّعت ليبيا على قدوم العمالة، وقد وقعت اتفاقيات ثنائية ومتعددة

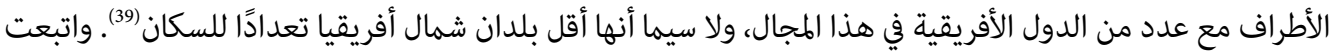
الدولة الليبية سياسة الأبواب المفتوحة للمهاجرين من الدول العربية والأفريقية، في ظل حاجتها إلى العمالة الأجنبية المدربة، وذات الخبرة خاصة في قطاعي الزراعة والطاقة. وقد استطاع العقيد معمر القذافي (1942-2011) تحويل ورقة المهاجرين في ليبيا إلى ورقة ضغط يلوّح بها في وجه دول الاتحاد الأوروبي لتحقيق مكاسب سياسية واقتصادية (40).

تبنّى القذافي مفهومَ التضامن الأفريقي في مؤتمر القمة غير العادية لمنظمة الوحدة الأفريقية في مدينة سرت في

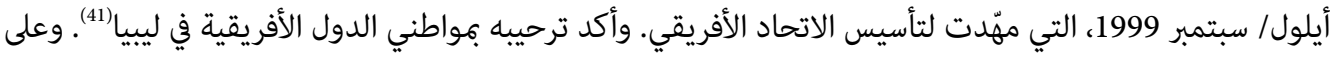

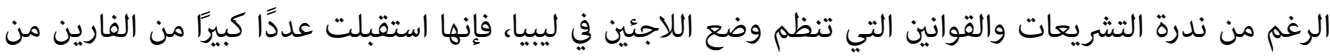
النزاعات من الصومال وإريتريا والسودان وفلسطين. وبقي مفهوم اللجوء محكومًا بتصورات العقيد القذافي، وبخاصة أن ليبيا لم تصدّق اتفاقية عام 1951 الخاصة باللاجئين (42)، لكنها التزمت بمبدأ عدم الإعادة القسرية، وسمحت

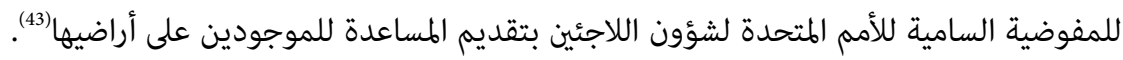

36

37 Sylvie Berdeloup \& Oliver Pliez, "Lybian Migration Corridor," European University Institute, Robert Schuman Center for Advanced Studies (2011), p. 6, accessed on 9/9/2019, at: https://bit.ly/2mF2SHH

38 Ibid.

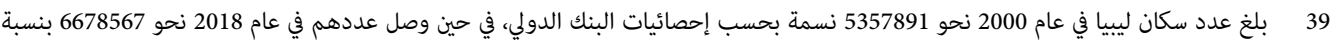

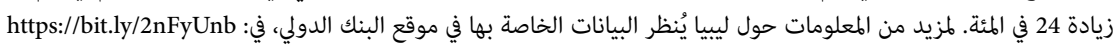

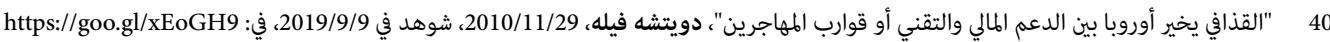

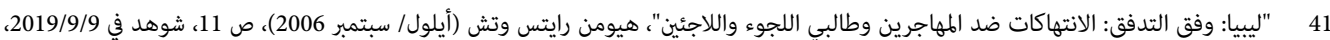
https://goo.gl/qmEqYK في فئن:

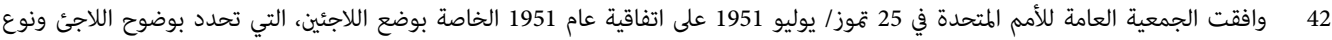

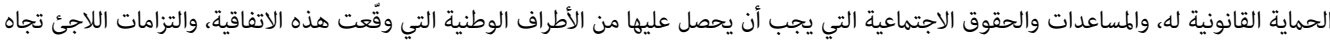

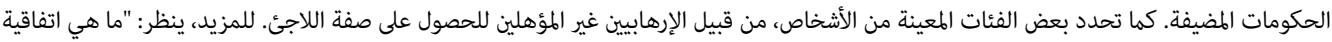

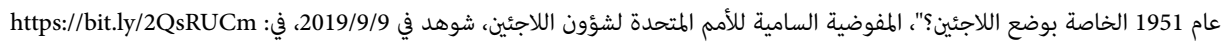

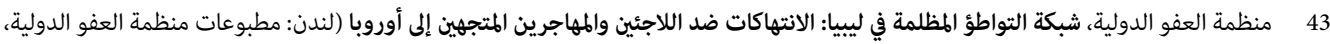

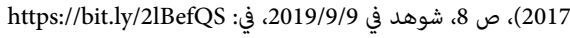


تعتبر مصلحة الجوازات والجنسية وشؤون الأجانب الجهة الرسمية في ليبيا المخوّلة بتنظيم عمليات دخول الأجانب وخروجهم منها، وقد نظّمت مواد القانون رقم (6) الصادر في عام 1987 حركة دخول الأجانب إلى الأراضي الليبية، وجرّمت دخولهم بصورة غير قانونية(44). وقد عدّلت السلطات الليبية القانون رقم (6) وأصدرت القانون رقم (2) في عام 2004، حيث نصّت المادة رقم (2) من القانون الجديد على إضافة مادة جديدة إلى القانون رقم (6) تجرّم تهريب المهاجرين بأي وسيلة، والحكم بالسجن مدةً لا تقل عن عام واحد ودفع غرامة لا تقل عن ألف دينار ليبي لمن يثبت تورطه في تهريب الأجانب(45).

يعدّ القانون رقم (19) لسنة 2010 بشأن مكافحة الهجرة غير النظامية أهم التشريعات والقوانين المعمول بها في مجال تنظيم اللجوء السياسي والإنساني في ليبيا. وبموجب هذا القانون تملك السلطات الحق في احتجاز المهاجرين من دون تصريح بوجودهم في ليبيا لأجل غير مسمى، بصرف النظر عن عمر المحتجز. ولا توجد إجراءات رسمية

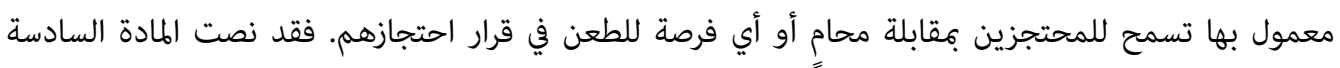
من القانون رقم (19) على معاقبة "الأجنبي المهاجر غير الشرعي بعقوبة الحبس مع الشغل أو بغرامة لا تزيد

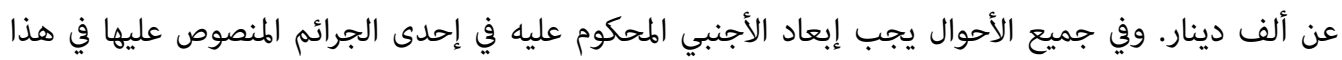

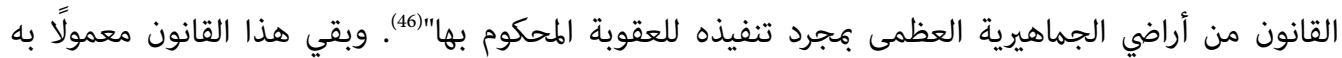
حتى بعد سقوط نظام القذافي، حيث يتم تجميع المهاجرين في مراكز احتجاز Detention Centers منتشرة في ليبيا في مدن طرابلس، ومصراتة، وتاجوراء وغيرها، في ظروف غير إنسانية ولفترات طويلة قبل عملية الترحيل ومن دون مراجعة قضائية. ويعد هذا مِنزلة احتجاز تعسفي يحظره القانون الدولي. وقد قامت وزارة وارة العدل في في عام 2013 بإعداد مشروع قانون بشأن "الاتجار بالبشر" تحت إشراف مكتب الأمم المتحدة المعني بالمخدرات والجريمة United Nations Office on Drugs and Crime التشريعية الليبية. وقد سن القانون رقم (10) الصادر في عام 2013 بشأن "التعذيب والاختفاء القسري والتمييز".

\section{1. ليبيا: من بلد المقصد إلى بلد العبور}

شهدت ليبيا بعد عام 2000 ارتفاعًا في عدد المقيمين الأجانب، حيث نشطت ظاهرة الهجرة غير النظامية من بلدان أفريقيا جنوب الصحراء نحو ليبيا، ثم الانطلاق من سواحلها نحو سواحل دول الاتحاد الأوروبي، باستخدام قوارب مطاطية غير صالحة للملاحة مسافاتٍ طويلة. لقد تحوّلت ليبيا إلى مكان يقيم فيه المهاجر بغرض العمل والإقامة

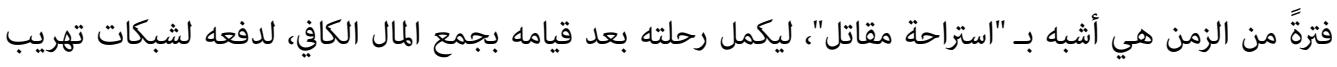
البشر إلى القارة الأوروبية. ولكن السلطات الليبية استطاعت ضبط حركة الهجرة غير النظامية انطلاقًا من سواحلها. 44 "قانون رقم (6) لسنة 1987 بشأن تنظيم دخول وإقامة الأجانب في ليبيا وخروجهم منها"، مركز جنيف لحوكمة قطاع الأمن "ديكاف"، 1987/6/2019،

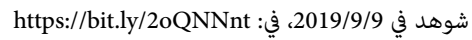
45 "قانون رقم (2) لسنة 2004 بشأن تعديل بعض أحكام القانون رقم (6) لسنة 1987 إفرنجي بشأن تنظيم دخول وإقامة الأجانب في ليبيا"، مركز جنيف

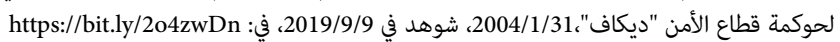

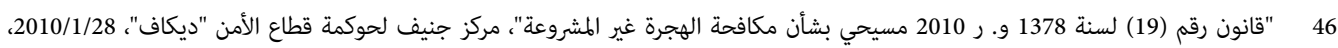
شوهد في 2019/9/9، في: شقن (19) 
واستضافت ليبيا في عام 2009، أي قبل عامين فقط من اندلاع ثورة 17 فبراير، على أراضيها نحو 2.5 مليون مهاجر، قادمين من دول أفريقية، وكذلك آسيوية، وبخاصة من بنغلاديش والفلبين. وخلال الفترة 2000-2011 وصل إلى

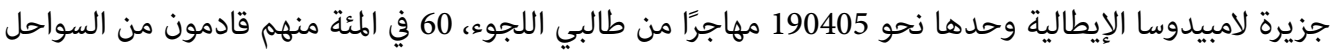

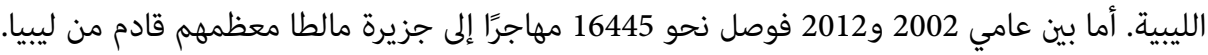

كان التحول الأساسي الذي ساهم في وضع ليبيا من جديد على خريطة الهجرة غير النظامية، ونقلها من بلد مقصد إلى بلد عبور للمهاجرين، هو تدهور البيئة الأمنية فيها، بدءًا من الصراع في عام 2012 الذي أعقبه انزلاق البلاد في مهادي

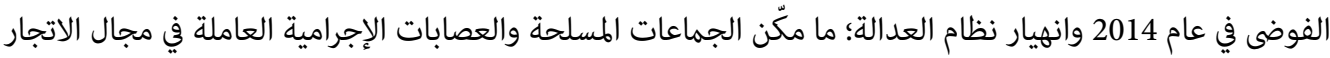
بالبشر من الإفلات من العقاب. وفُقدت السيطرة على حركة المهاجرين عبر البلاد في ظل غياب شبه كامل مؤسسات الدولة الأمنية والعسكرية (47). وبناء عليه، زادت موجات الإت هجرة مندات الرعايا الليبيين والعمالة الأجنبية، إضافة الى المهاجرين

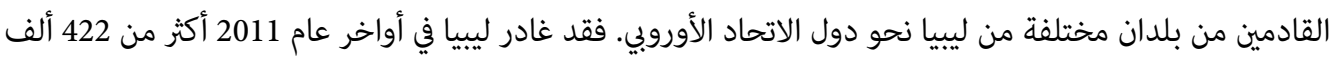
مواطن ليبي، و768 ألف مهاجر بسبب الصراع الداخلي وفق ما جاء في تقرير الهجرة الدولية لعام 2015 (48). واتجه معظمهم إلى تشاد وتونس والجزائر ومصر. وكان عدد كبير منهم من مواطني البلدان التي عادوا إليها. وقد بلغت نسبة المهاجرين منهم من بلدان أخرى نحو 41 في المئة احتاجوا إلى مساعدات كبيرة للعودة إلى أوطانهم. وعلى الرغم من عودة عدد كبير من المواطنين الليبيين إلى بلدهم بعد سقوط نظام العقيد القذافي، وبدء المرحلة

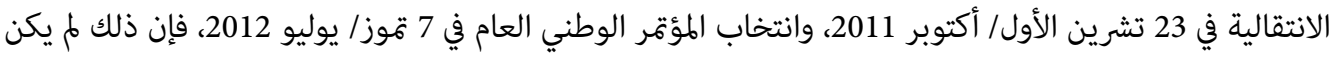

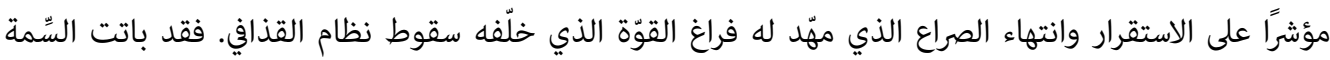
البارزة للبلاد هي فوضى السلاح المنتشر لدى الكتائب المسلحة التي لا تخضع لأيّ سلطة مركزية؛ ما سمح لهاء بهلء الفراغ الذي خلّفه انهيار أجهزة الدولة الأمنية والعسكرية.

ساهم قرار المجلس الوطني الانتقالي، تحت ضغط الكتائب المسلحة، بدفع أجور لأعضاء هذه الكتائب من الخزينة

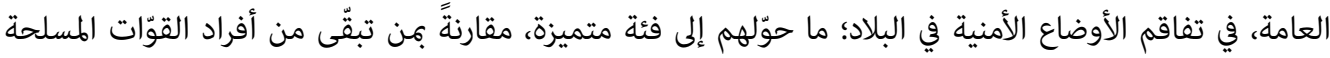

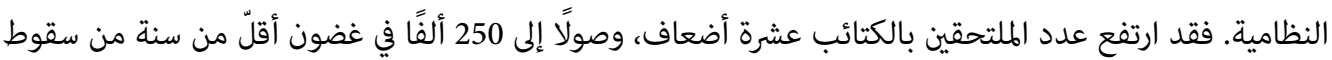
القذافي (49). وقد تعاقبت على ليبيا مجموعة من الحكومات، لكنّها فشلت في تحقيق الاستقرار وحلّ الأزمات السياسية والاقتصادية ومنها إدارة الهجرة غير النظامية.

جرت انتخابات تشريعية في عام 2014، جاءت نتائجها في غير مصلحة التحالف الثوري المُهيمِن على المؤتمر الوطني

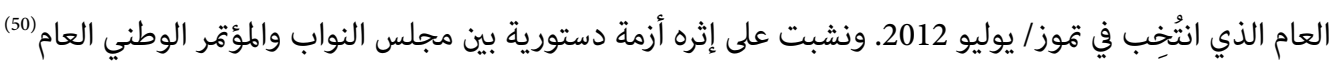
لدى انعقاد مجلس النواب في طبرق في 2 آب/ أغسطس 2014، ما عزّز الاستقطاب السياسي في البلاد التي دخلت

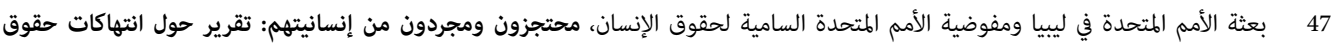

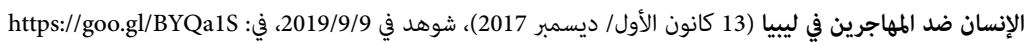

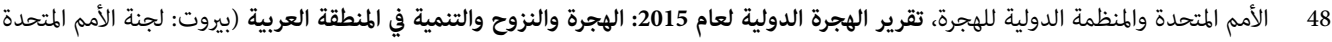

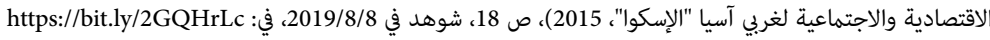
49 ج 4 جلبير الأشقر، انتكاسة الانتفاضة العربية: أعراض مرضية (بيروت: دار الساقي، 2016)، ص ص 172. 
في نقق الاحتراب الداخلي؛ ما دفع العديد من رعايا الدولة الليبية واللقيمين إلى النزوح أو الهجرة خارج البلاد. فقد

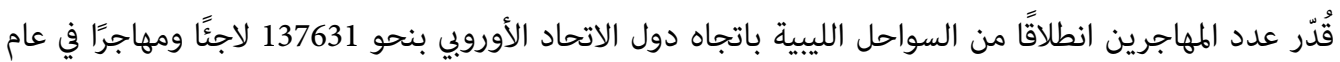

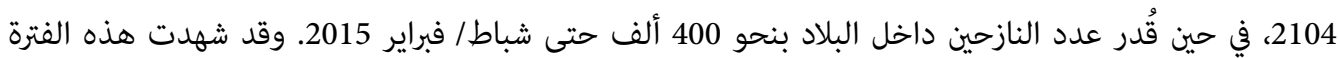
التي تزامنت مع النزاع الداخلي الليبي، وسيطرة تنظيم الدولة الإسلامية "داعش" على مساحات واسعة من العراق

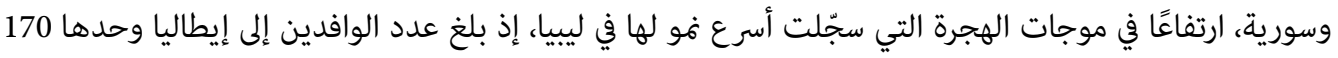
ألف شخص في عام 2014، أي ما يفوق أربع مرات عدد الوافدين المسجلين في عام 2013، وهو أكبر الأرقام المسجلة، ألهو

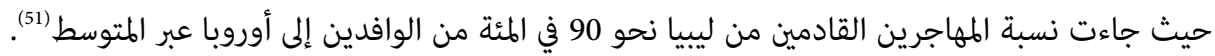

\section{2. مصفوفة تتبّع النزوح في ليبيا: 2018-2019}

قدّرت المنظمة الدولية للهجرة التابعة للأمم المتحدة في تقرير حول النزوح والهجرة غير القانونية في ليبيا "مصفوفة تتبع النزوح" Displacement Tracking Matrix, DTM

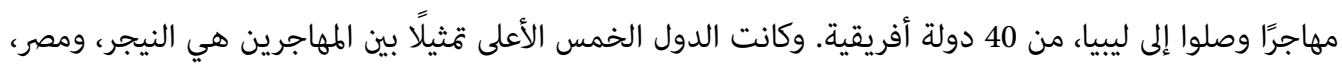
وتشاد، والسودان، وغانا على التوالي، وتمثل مجتمعة ما نسبته 66 في المئة من إجمالي المهاجرين في ليبيا، يقطنون بئنين في 99 بلدية و551 محلة. وجاء في التقرير أن 73 في المئة من مهاجري دول أفريقيا جنوب الصحاء أنساء الكبرى يقيمونه

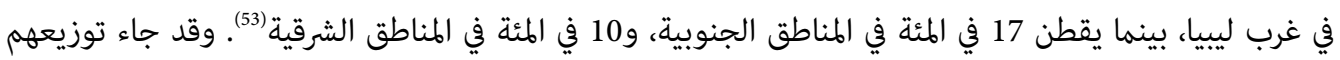
بحسب المناطق والبلديات على النحو التالي: العاصمة طرابلس حصلت على العدد الأكبر من المهاجرين، إذ تؤوي

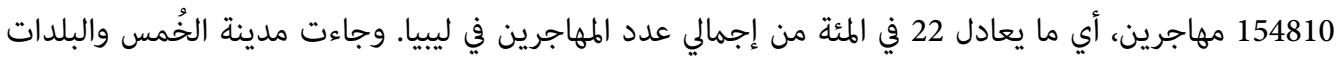

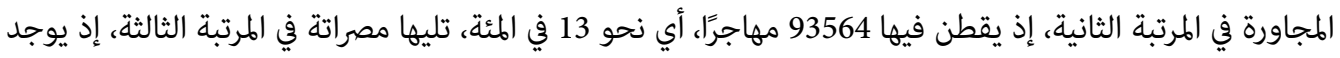

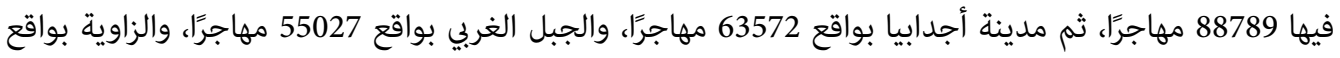
33228 مهاجرًا، وسبها بواقع 31100 مهاجر.

وذكرت المنظمة أن 92 في المئة من المهاجرين، أي ما يعادل 650073 مهاجرًا، يأتون من 31 دولة أفريقية، في حين

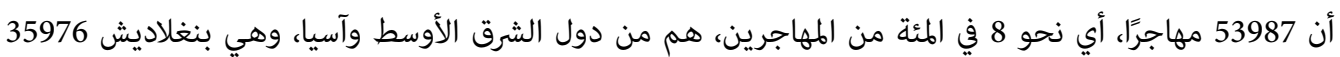

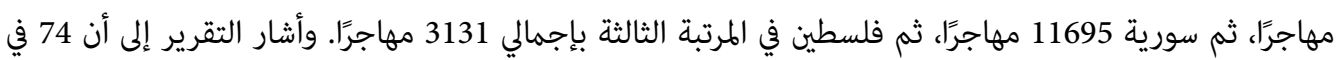
المئة من مهاجري آسيا في ليبيا يقيمون في المناطق الغربية، في حين يقيم 25 في المئة في الشرق، وا 1 في المئة في الجنوب. وبحسب بيانات المنظمة، فإن البالغين يمثلون 90 في المئة من المهاجرين الموجودين في ليبيا، ويثّل الرجال

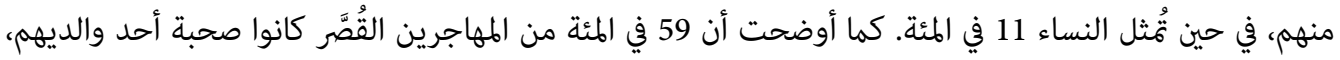

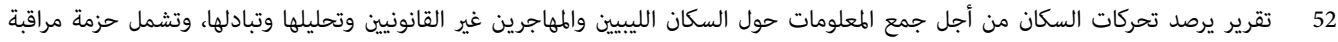

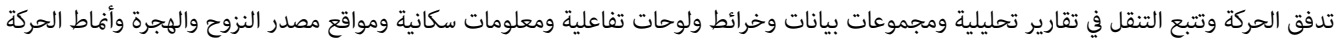

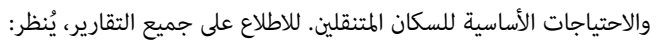
The UN Migration Agency, IDP and Returnee Report, Round 26: Libya Mobility Tracking, Displacement Tracking Matrix (June-July 2019), accessed on 9/9/2019, at: http://bit.ly/2OwEzYh

53 The UN Migration Agency, Libya's Migrant Report, Round 17: Flow Monitoring, Displacement Tracking Matrix (January-February 2018), accessed on 9/9/2019, at: https://goo.gl/BCoHUY 
في حين كان 41 في المئة منهم من دون مرافقين (54. وتُظهر الأرقام حجم الهجرة غير القانونية في ليبيا باعتبارها بلدًا مصدّرًا للمهاجرين في اتجاه أوروبا، والذي تقف خلفه شبكات تهريب منظمة تستفيد من حالة الفوضى وانعدام

$$
\text { الأمن والاستقرار الداخلي. }
$$

ومقارنةً بكصفوفة تتبع النزوح واللجوء في ليبيا التي أعدتها المنظمة الدولية للهجرة خلال الفترة 13 حزيران/ يونيو - 4 آب/ أغسطس 2019، نلحظ عدم وجود فرق كبير في أعداد المهاجرين في ليبيا، حيث قدّر

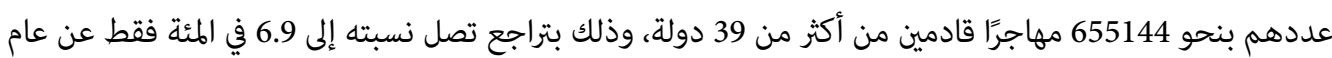
2018. وقد كان توزيعهم على النحو التالي: جاء نحو 602216 مهاجرًا، أي ما نسبته 92 في المئة، من 19 دولة أفرئه

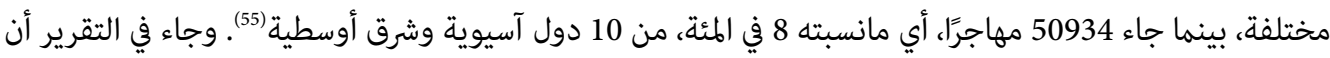

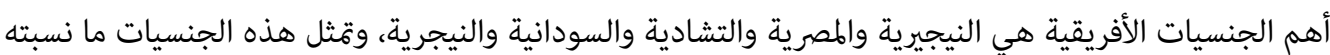
71 في المئة من المهاجرين الذين تم تحديدهم في ليبيا (ينظر الجدولان 1 و2).

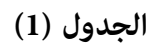

\begin{tabular}{|c|c|c|c|c|c|}
\hline المغرب & الجزائر & ت تونس & السودان & مصر & دول شمال أفريقيا \\
\hline 3 & 1 & 4 & 40 & 52 & 195311 مهاجرًا \\
\hline
\end{tabular}

\section{النسب المئوية للمهاجرين من دول شمال أفريقيا إلى ليبيا في عام 2019}

المصدر: من إعداد الباحث استنادًا إلى تقرير مصفوفة تتبع النزوح في ليبيا، في:

The UN Migration Agency, IDP and Returnee Report, Round 26: Libya Mobility Tracking, Displacement Tracking Matrix (June-July 2019), accessed on 9/9/2019, at: http://bit.ly/2OwEzYh

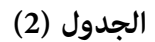

\begin{tabular}{|c|c|c|c|c|c|c|c|c|c|c|c|c|c|}
\hline ב) & ;: & $\begin{array}{l}\frac{3}{3} \\
\frac{3}{3}\end{array}$ & $\begin{array}{c}\frac{2}{3} \\
\frac{3}{2} \\
\frac{9}{3}\end{array}$ & $\frac{9}{9}$ & $\stackrel{9}{=}$ & 象: & 3 & $\begin{array}{l}\overline{\bar{b}} \\
\frac{3}{5} \\
.3\end{array}$ & 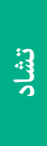 & :3: & $\begin{array}{l}\overline{3} ; \\
3 ;\end{array}$ & $\begin{array}{l}\overline{3} \\
3 \\
3\end{array}$ & جنوب أفريقيا \\
\hline 1 & 2 & 1 & 1 & 9 & 7 & 32 & 14 & 1 & 24 & 1 & 2 & 3 & $\begin{array}{l}406905 \\
\text { مهاجرين }\end{array}$ \\
\hline
\end{tabular}

النسب المئوية للمهاجرين من دول أفريقيا جنوب الصحراء إلى ليبيا في عام 2019

المصدر: المرجع نفسه.

أما الجنسيات الآسيوية والشرق أوسطية فهي من سورية، وفلسطين، وباكستان، وبنغلاديش، ويوضح الجدول (3)

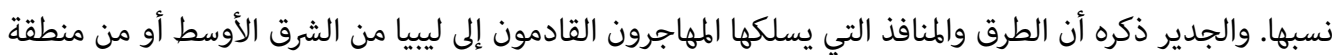
القرن الأفريقي أو منطقة أفريقيا جنوب الصحراء في أغلبها محفوفة بالمخاطر والصعوبات. 


\section{الجدول (3)}

النسب المئوية للمهاجرين من دول آسيوية وشرق أوسطية إلى ليبيا في عام 2019

\begin{tabular}{|c|c|c|c|c|}
\hline بنغلاديش & باكستان & فلسطين & سورية - & الدول الآسيوية والشرق أوسطية \\
\hline 46 & 3 & 10 & 36 & 50934 مهاجرًا \\
\hline
\end{tabular}

المصدر: المرجع نفسه.

لقد تزامن إعداد تقرير مصفوفة تتبّع النزوح في عام 2019 مع النزاع المسلح الذي بدأه اللواء المتقاعد خليفة حفتر في الرابع من نيسان/ أبريل 2019، وهو ما أثر سلبيًا في وضع المهاجرين والنازحين في مناطق النزاع المسلح، وزاد من احتمالات تعرضهم للأذى. كما انخفضت فرص حصولهم على العمل، ومن ثمّ، على الهال اللازم لسد احتياجاتهم الإنسانية. وانسحب الأمر نفسه على مدينة مرزق في الجنوب الليبي، فقد ضربت غارات جوية مركز احتجاز تاجوراء في الثاني من توز/ يوليو 2019 الذي يوجد فيه عدد من المهاجرين، ما أودى بحياة 53 مهاجرًا، وأصيب 87 آخرون.

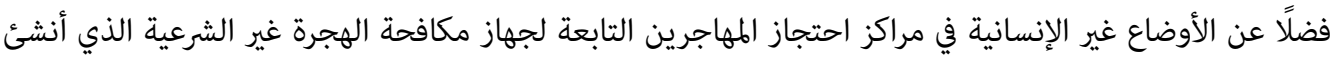
في عام 2012 ويتبع وزارة الداخلية في ليبيا. ومعظم تلك المراكز عبارة عن مستودعات ومبانٍ لا تصلح لاحتجاز الأشخاص، وتتسم بالاكتظاظ الشديد ونقص المرافق الصحية وانتشار الأمراض المعدية، ولا تتمتع السلطات الليبية

بالقدرة والإمكانية للوصول إلى تلك المراكز التي تخضع إدارتها للكتائب والميليشيات التي تتبع المدينة أو البلد (56). وبناءً على البيانات الواردة في تقريري مصفوفة تتبّع النزوح في ليبيا، يمكن الوقوف على مجموعة من الأسباب التي تقف وراء تدفقات المهاجرين غير النظاميين من ليبيا نحو دول الاتحاد الأوروبي، منها:

ه قوة شبكات التهريب والاتجار بالبشر: نشطت تلك الشبكات في البلاد نتيجة الفوضى، وساعدها في ذلك قوتها وتنظيمها وامتلاكها السلاح، إضافة إلى السيطرة على مناطق جغرافية وقواعد لوجستية (منازل، وقوارب، واتصالات ...إلخ)، فضًا عن قدرتها على الإفلات من القوة الحكومية. ه عامل الجذب الاقتصادي: على الرغم من تدهور الأوضاع الاقتصادية في ليبيا، فإن المهاجرين عادة ما يتمكنون

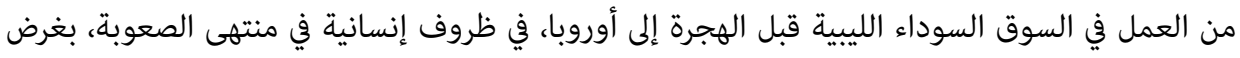
جمع المال الذي يمكنهم من العبور إلى الضفة الأخرى من المتوسط. † الحدود الرخوة: تسمح سياسات إدارة الحدود المعتمدة بين الدول الأفريقية وليبيا بنشاط مهربي البشر، إضافة إلى عدم قدرة حكومة الوفاق الوطني على ضبط الحدود الجنوبية، وصعوبة الرقابة على الحدود التي أغلبها في الصحراء بطول 4400 كيلومتر مع ست دول (تشاد، والنيجر، والسودان، والجزائر، وتونس، ومصر). ه تعارض إرادات دول الجوار: عدم التعاون بين الدول المجاورة تعاونًا جديًا لضبط مسألة الهجرة؛ فالاتفاقيات الثنائية مع تشاد والسودان والجزائر وتونس في عام 2012، ومع مصر في عام 2013 بشأن ضبط الحدود لم تسفر عن تعاون منهجي. ولم يكن لها أي تأثير يذكر في الحد من تدفق المهاجرين، أو التخفيف من 
نشاط الشبكات الإجرامية لتهريب المهاجرين والاتجار بهم عبر الحدود البرية نتيجة تعارض استراتيجياتها ومقارباتها لحل الأزمة الليبية. † السمعة: أدت الأزمات الإنسانية والسياسية في بلدان المصدر، سواء من دول أفريقية أو دول المشرق العربي، إلى دفع المهاجرين إلى المخاطرة واختيار ليبيا رغم علمهم بخطورة الوضع الأمني، الذي يماثل أو يزيد في خطورته وضع بلدانهم. إلا أن سمعة ليبيا المرتبطة بسهولة الانتقال من سواحلها إلى أوروبا، ساهمت في في

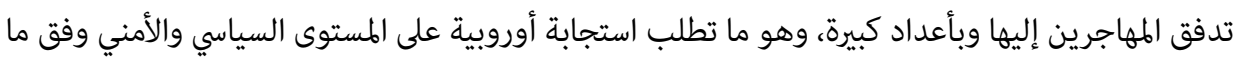

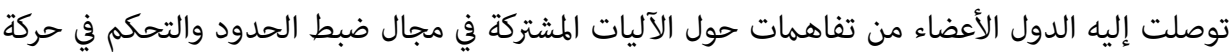
الأفراد وتنقلهم.

\section{ثالثًا: استجابة الاتحاد الأوروبي للهجرة غير النظامية في ليبيا}

جاءت استجابة الاتحاد الأوروبي لمواجهة معضلة الهجرة غير النظامية في ليبيا، انسجامًا مع التطورات التي طرأت على معات التهات العمل الأوروبي المشترك في مجال إدارة الهجرة، وفق التوجيهات والتشريعات التي صدرت عن المفوضية الأوروبية

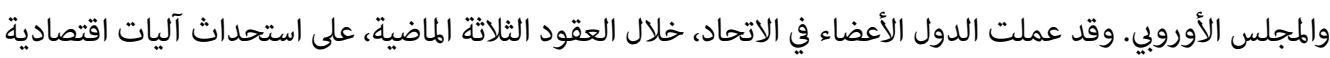

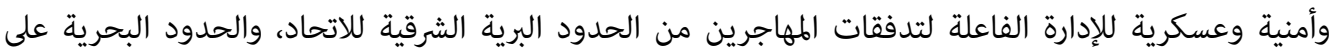

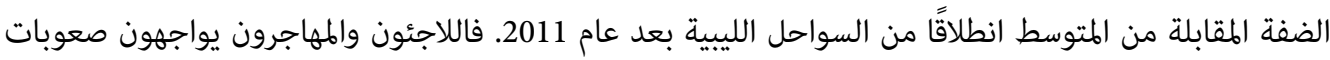
شديدة في رحلتهم، إذ وصلت حد غرق عدد كبير من السفن التي تحملهم. ويأتي ذلك في ظل انهيار شبه كامل

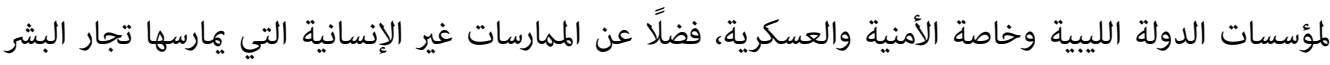
على المهاجرين. وقد وجّهت منظمات حقوقية نقدًا إلى السلطات الليبية مرات عديدة، وذلك بسبب فشلها في ضمان واحترام حقوق اللاجئين والههاجرين الذين يُجمّعون في مراكز احتجاز في ظروف غير لائقة إنسانيًا، ويخضعون مرئ لخطر الإعادة القسرية، وهو الإجراء الذي عدّته المحكمة الأوروبية لحقوق الإنسان في عام 2012 إجراءً غير قانوني،

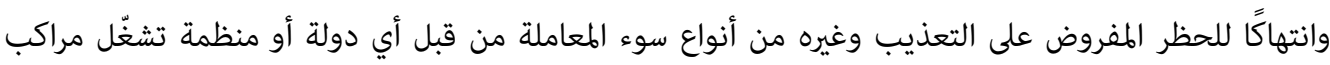

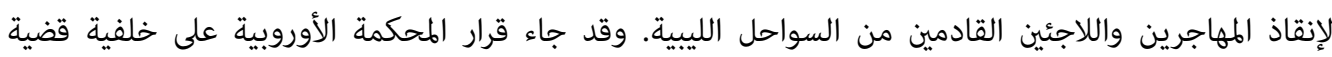
عiris Jamma and others vs Italy على متنها أحد عشر صوماليًا وثلاثة عشر إريتيريًا وأعادتهم إلى طرابلس (57). وقد التزمت الدول فينات الأعضاء منذ عام 2013 بقرار المحكمة؛ فقد أطلقت السلطات الإيطالية عملية ماري نوستروم Operation Mare Nostrum، في 18 تشرين الأول/ أكتوبر 2013، لإنقاذ المهاجرين واللاجئين القادمين من السواحل الليبية الذين ارتفعت أعدادهم

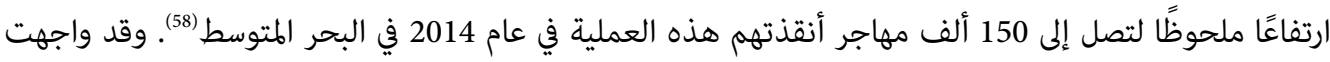
الحكومة الإيطالية على إثر ذلك ترددًا من جانب الدول الأعضاء في الاتحاد في اقتسام المسؤولية في استقبال المهاجرين القادمين من ليبيا. وقد بلغ الخلاف الأوروبي ذروته بين الدول المطلة على المتوسط ودول أوردان أوروبا الشمالية، ما قاد

57 The European Court of Human Rights, Case of Hirsi Jamaa and Others v. Italy: (Application no. 27765/09), 23/2/2012, accessed on 9/9/2019, at: https://bit.ly/2n0UxL9

58 "IOM Applauds Italy's Life-Saving Mare Nostrum Operation: 'Not a Migrant Pull Factor'," Missing Migrants Project, International Organization for Migration, 31/10/2014, accessed on 9/9/2019, at: https://bit.ly/2mFKj6F 
المفوضية الأوروبية في حزيران/ يونيو 2016 إلى الإعلان عن إطار جديد لشراكات مع بلدان المصدر والعبور، وهو عبارة عن حزم مساعدات مخصصة لتطوير قدرات الاستقبال المستدامة والآمنة للمهاجرين في بلدان المصدر والعبور، إستر مثل النيجر ومالي ونيجيريا وإثيوبيا والسنغال وليبيا، وتكين المهاجرين واللاجئين من البقاء في بلدانهم وتجنّب القيام

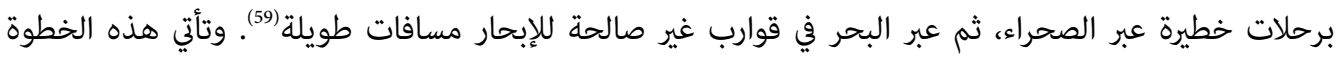

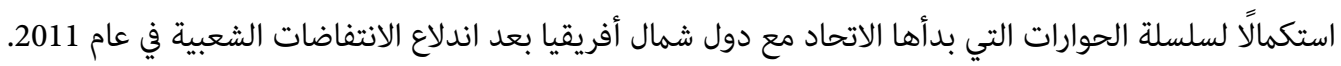

\section{1. إعلان مالطا: خطوة نحو ضبط الهجرة غير النظامية من السواحل الليبية}

تبنى الاتحاد الأوروبي في الثالث من شباط/ فبراير 2017 إعلان مالطا Malta Declaration الذي ركز على حركة الأفراد غير النظامية بين ضفتي المتوسط، وبموجبه اتفقت الدول الأعضاء في الاتحاد على إعطاء أولوية لتقديم التدريب والمعدات اللازمة لخفر السواحل الليبي وغيره من الأجهزة ذات الصلة، وعلى اتخاذ تدابير تضمن تهيئة الظروف المناسبة لاستقبال السلطات الليبية للمهاجرين، وذلك بالتعاون مع المفوضية السامية للأمم المتحدة لشؤون التهني اللاجئين والمنظمة الدولية للهجرة(60). كما تطرّق إعلان مالطا إلى مذكرة التفاهم بين الجانبين الإيطالي والليبي في

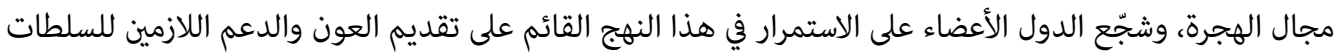
الليبية في مكافحة الهجرة غير النظامية. وقد تضمنت مذكرة التفاهم تقديم السلطات الإيطالية الدعم الفني والتقني والتدريب والدعم المالي، ليس لخفر السواحل الليبية فحسب، بل لوزارة الداخلية في حكومة الوفاق الوطني المسؤولة

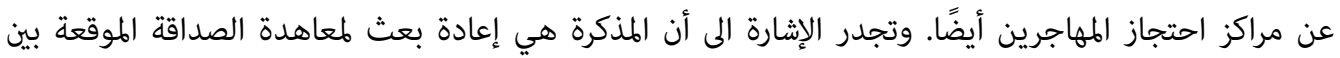
البلدين في عام 2009.

وفي هذا الصدد، وتنفيذًا لبنود إعلان مالطا، وبناءً على توصية من المفوضية الأوروبية، اعتمد الصندوق الائتهاني

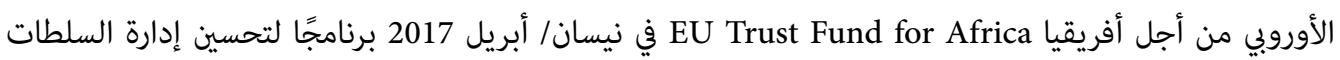

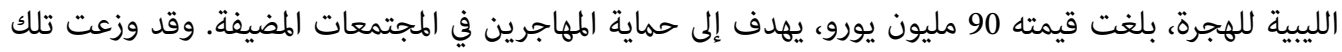
المساعدات على قسمين، خصص القائون على البرنامج 48 مليون يورو لحماية المهاجرين واللاجئين في مراكز الاحتجاز، وتقديم الخدمات الصحية والإسعافات الأولية والنفسية اللازمة، وعمليات العودة الطوعية وإعادة دمج المهاجرين في مجتمعاتهم الأصلية، في حين خُصص 42 مليون يورو لتحسين التنمية الاجتماعية والاقتصادية على مستوى البلديات

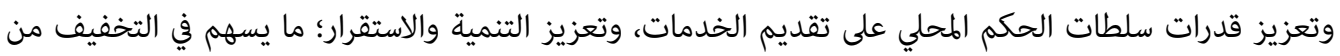
اعتماد المجتمعات المحلية في الجنوب الليبي على تجارة وتهريب البشر وسيلةً للكسب المالي (61). وقد استند الاتحاد

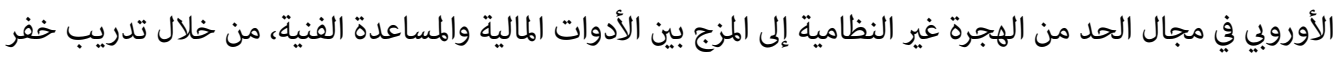

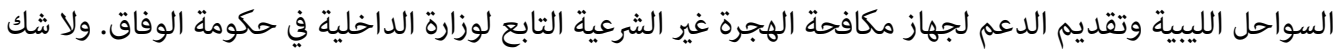
في أن هذا النهج قد يسهم في تقليل تدفقات المهاجرين، لكنه في الوقت ذاته حل مؤقت وغير مستدام لأزمة الهجرة.

59 "Communication from the Commissionon Establishing a New Partnership Framework with Third Countries under the European Agenda on Migration," Eur-Lex, 7/6/2016, accessed on 9/9/2019, at: https://bit.ly/2nkcYxR

60 "Malta Declaration by the Members of the European Council on the External Aspects of Migration: Addressing the Central Mediterranean Route," European Council, 3/2/2019, accessed on 0/9/2019, at: https://bit.ly/2QH80VI

61 "EU Trust Fund for Africa Adopts €90 Million Programme on Protection of Migrants and Improved Migration Management in Libya," European Commission, 12/4/2017, accessed on 9/9/2019, at: https://bit.ly/2nEVHzG 


\section{2. العمليات الأوروبية قبالة الشواطنئ الليبية: عمليتا تريتون وصوفيا}

قامت السلطات الإيطالية بوقف عمليات ماري نوستروم بعد نحو عام من انطلاقها، وقد ساهمت في الحد من تكرار مآسي غرق قوارب المهاجرين وإنقاذهم في عرض البحر المتوسط. وقد لاقت هذه الخطوة انتقادًا واسعًا من المنظمات الدولية كمنظمة العفو الدولية، ومنظمة "أنقذوا الأطفال" Save the Children، وعدد من الجمعيات المحلية الإيطالية، مثل: "آرشي"Arci، و "آرشي" Arci، و"كاريتاس" Caritas، التي رأت فيها تراجعًا للدور الإنساني الذي تقوم الجمات به إيطاليا في مجال إنقاذ الطهاجرين. توجّه الاتحاد الأوروبي نحو إطلاق عملية مشتركة في الأول من تشرين الثاني/ نوفمبر 2014 لإدارة الهجرة غير النظامية،

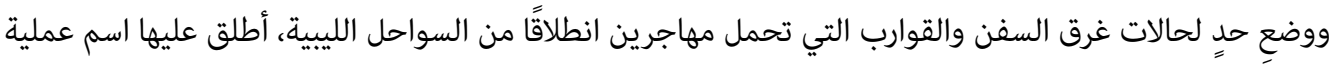

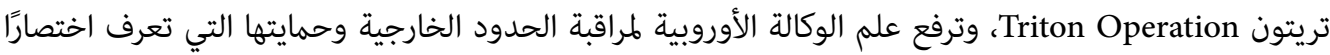
بفرونتكس Frontex لامبيدوسا، والثانية من ميناء إمبيدوكله Empedocle في جنوب جزيرة صقلية، وتسير دورياتها لمراقبة حركة قوارب لتئي المهاجرين على مسافة 30ميلًا بحريًا من السواحل الإيطالية، ولديها القدرة على الاقتراب من السواحل الليدية الليبية للقيام بعمليات إنقاذ السفن والقوارب التي تواجه خطر الغرق في المياه الإقليمية الليبية. مل يُكتب لعملية تريتون النجاح في الحد من تدفقات المهاجرين أو حتى الحد من غرق السفن التي تقلّ

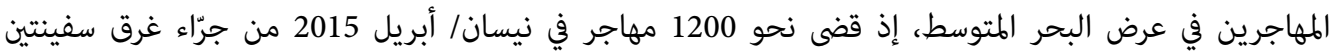

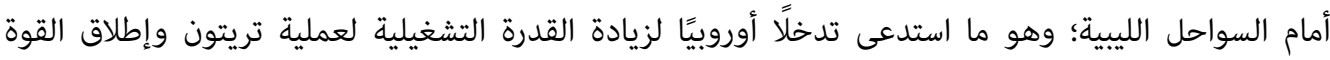
البحرية الأوروبية EUNAVFOR MED في المتوسط في 22 حزيران/ يونيو 2015 التي حملت اسم عملية صوفيا Sophia Operation المشتركة للاتحاد الأوروبي، بهدف محاربة الهجرة وعمليات الاتجار بالبشر، والطساهمة في تعزيز قدرة الاتحاد الأوروبي على تحقيق الاستقرار والأمن في ليبيا، ومنطقة البحر المتوسط الذي يشهد حركة متزايدة لقوارب وسفن المهاجرين غير النظاميين. كما تقوم عملية صوفيا بهمات أخرى، أهمها:

ه تدريب خفر السواحل والبحرية الليبية، ومتابعة كفاءة التدريبات على المدى الطويل في محاربة شبكات الاتجار بالبشر والحد من الهجرة غير النظامية.

62 تأسست في عام 2004 بهوجب لائحة المجلس الأوروبي رقم 2004/2007 الصادرة في 26 تشرين الأول/ أكتوبر 2004، وهي المسؤولة في المقام الأول

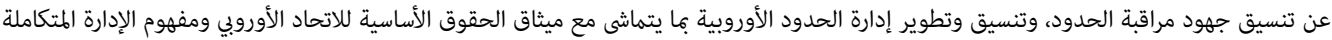

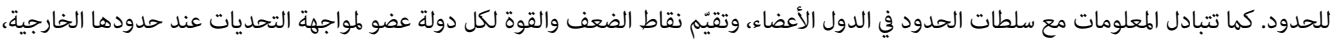

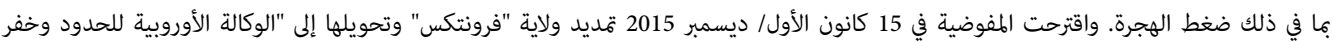

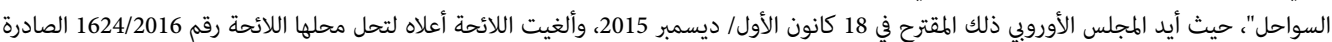

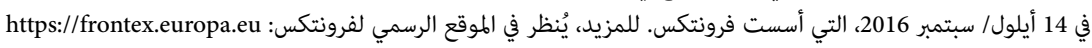
"Council Regulation (EC) No 2007/2004 of 26 October 2004 Establishing a European Agency for the Management of Operational Cooperation at the External Borders of the Member States of the European Union," Eur-lex, 25/11/2004, accessed on 9/9/2019, at: https://bit.ly/2oypSZR; "Regulation (EU) 2016/1624 of the European Parliament and of the Council of 14 September 2016 on the European Border and Coast Guard and Amending Regulation (EU) 2016/399 of the European Parliament and of the Council and Repealing Regulation (EC) No 863/2007 of the European Parliament and of the Council, Council Regulation (EC) No 2007/2004 and Council Decision 2005/267/EC," Eur-lex, 16/9/2016, accessed on 9/9/2019, at: https://bit.ly/2or6UUP 
ه المساهمة في تنفيذ حظر الأسلحة الذي تفرضه الأمم المتحدة على أعالي البحار قبالة ساحل ليبيا.

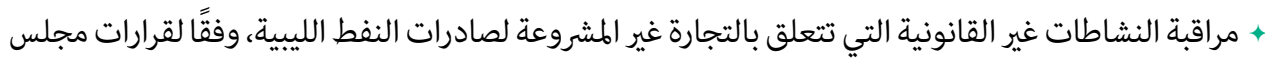

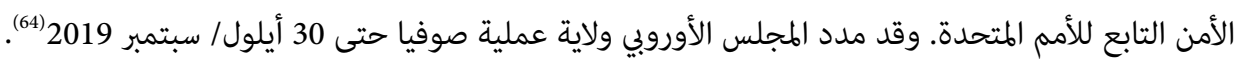

\section{3. المساعدة في ضبط الحدود الليبية البحرية والبرية وتدريب خفر السواحل}

قام الاتحاد الأوروبي عبر عملية صوفيا بتوقيع مذكرة تفاهم مع خفر السواحل وقوات البحرية الليبية في

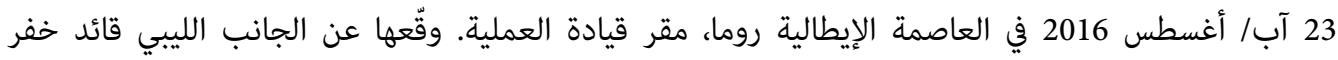

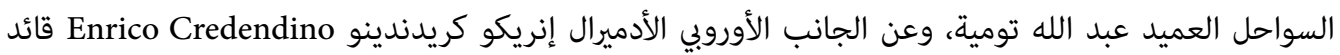

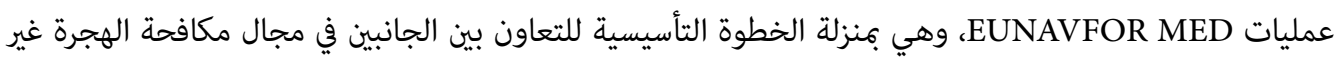
النظامية. ووفق مذكرة التفاهم، أجرت قيادة عملية صوفيا في 26 تشرين الأول/ أكتوبر 2016 تدريبات لـ لـ 78 متدربًا

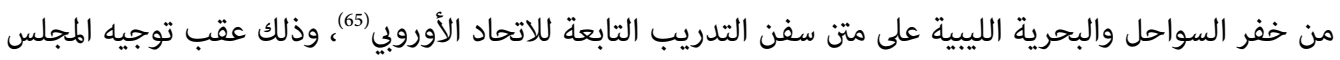

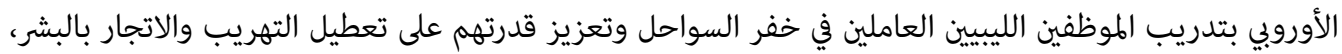

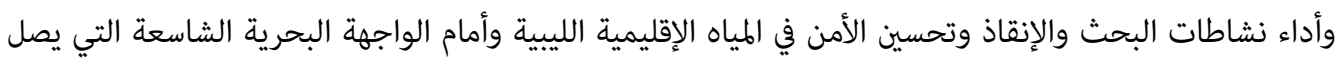

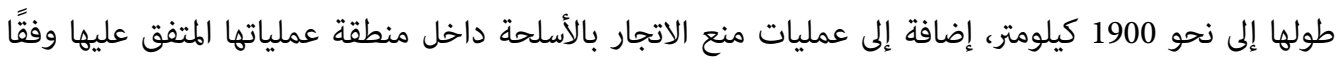

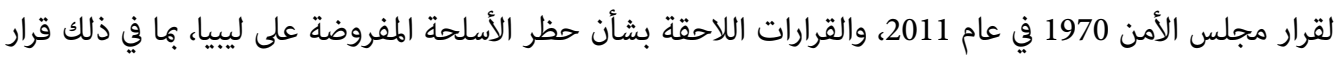
مجلس الأمن رقم 2292 في عام 2016(66). وقد بدأت عملية صوفيا بتدريب الدفعة الثانية من خفر السواحل في كانون الثاني/ يناير 2017 في مركز تدريب بحري في جزيرة كريت في اليونان، حيث تلقى 20 متدربًا من خفر السواحل

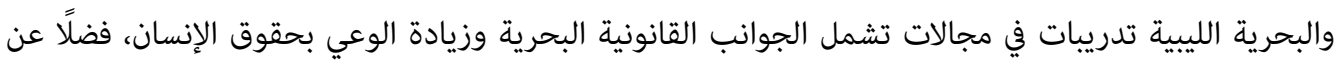

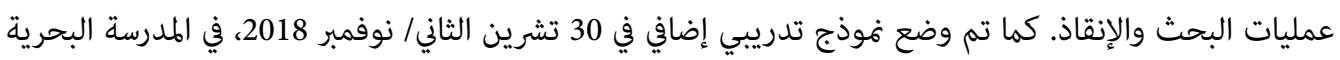

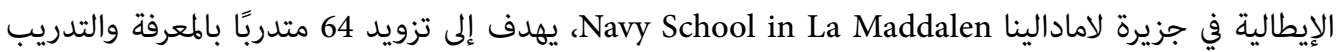
اللازمين للقيام بقيادة سفينة حراسة خارجية قبالة السواحل الليبية، إضافة إلى الدروس التي تركّز على حقوق لإمالى الإنسان والإسعافات الأولية الأساسية(67). لقد وصل عدد المتدربين من خفر السواحل الليبية إلى نحو 320 متدربًا ضمن برامج عملية صوفيا، كما خضع عدد من المتدربين في سبليت Split في كرواتيا، التي تقع على الساحل الشرقي للبحر

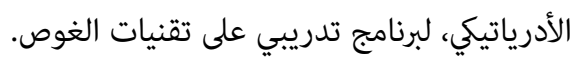

وأسس الاتحاد الأوروبي في 22 أيار/مايو 2013 بعثة مدنية لدعم السلطات الليبية في تحسين وتطوير أمن الحدود البحرية والجوية والبرية الليبية European Union Border Assistance Mission, EUBAM تابعة للسياسة

64 "EUNAVFOR MED Operation Sophia: Mandate Extended until 30 September 2019," European Council, 29/3/2019, accessed on 9/9/2019, at: https://bit.ly/2ms7i4r

65 "Operation SOPHIA: Package 2 of the Libyan Navy Coast Guard and Libyan Navy Training Launched Today," EU External Action, 30/1/2017, accessed on 9/9/2019, at: https://bit.ly/2nUJCGT

66 "Council Decision (CFSP) 2016/993 of 20 June 2016 Amending Decision (CFSP) 2015/778 on a European Union Military Operation in the Southern Central Mediterranean (EUNAVFOR MED operation SOPHIA)," Eur-Lex, 21/6/2016, accessed on 17/9/2019, at: https://bit.ly/2nb4rgY

67 "Operation SOPHIA: a Further Training Module for the Libyan Navy Carried Out in Italy," Operation Sophia Website, 3/12/1018, accessed on 9/9/2019, at: https://bit.ly/2nbpKPu 
الأمنية والدفاعية المشتركة للاتحاد الأوروبي. وتقدم البعثة للسلطات الليبية المشورة والتدريب والتوجيه وتعزز

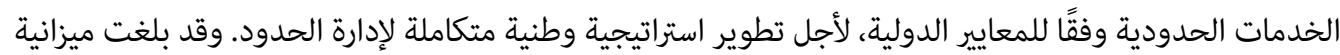
البعثة خلال الفترة 22 آب/ أغسطس 2016 - 21 آب/ أغسطس 2017 نحو 17 مليون يورو (68).

\section{خاتمة}

حكمت مقاربات الاتحاد الأوروبي لظاهرة الهجرة النظامية أو غير النظامية مسألتان: الأولى، التراجع الديموغرافي في دول الاتحاد وحاجتها إلى سد هذه الفجوة اعتمادًا على المهاجرين من ذوي الخبرة والكفاءة العملية والعلمية. والثانية، ارتباط ظاهرة الهجرة بهجموعة من التحديات الأمنية والاقتصادية والاجتماعية. توصلت الدول الأعضاء في الاتحاد إلى قناعة مفادها أن الأدوات التي تستخدمها في مجال إدارة الهجرة على المستوى القومي باتت غير كافي كافية،

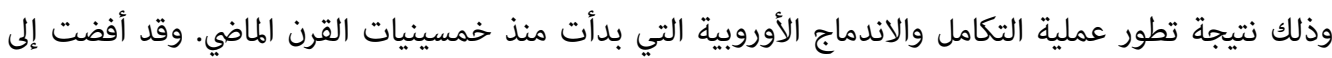
سلسة من الاتفاقيات والمعاهدات المشتركة ساهمت في وحدة الاتحاد وقاسكه، وخاصة بعد توقيع اتفاقية شينغن Schengen Agreement وأُلغيت القيود على حركة الأفراد والسلع.

طوّر الاتحاد سياسة مشتركة في مجال إدارة الهجرة، من خلال مراكمة عدد كبير من التشريعات والقوانين التي أقرتها

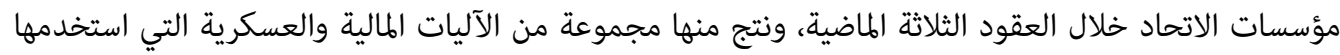
في إدارة تدفقات المهاجرين. ولا بد من الإثارة إلى أن تلك التشريعات والقوانين الأوروبية في مجال إدارة الهجرة منادية

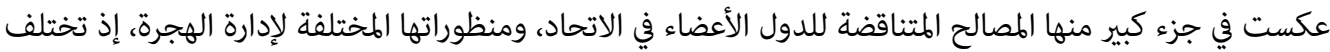
مقاربات الدول المطلة على البحر المتوسط عن مقاربات دول شمال أوروبا. ورغم التزام دول الاتحاد بتلك التشريعات والقوانين، فإنها تسعى لأن تبقى صاحبة اليد العليا في سنّ التشريعات والقوانين القومية في مجال إدارة الهجرة والمسائل المتعلقة بحركة انتقال الأفراد ضمن إقليمها (إصدار التأشيرات، وحجم العمالة الوافدة، ومراكز الإيواء، وبرامج الاندماج والتكامل ... إلخ).

وبالنظر إلى أزمة الهجرة انطلاقًا من الشواطئ الليبية، تستنتج الدراسة أن استجابة الاتحاد الأوروبي ارتهنت بضرورات

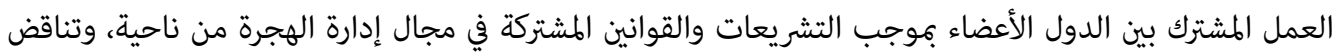
المصالح الاقتصادية والسياسية لتلك الدول تجاه الأزمة السياسية في ليبيا من ناحية أخرى؛ وهو ما قلل من فاعلية الأدوات المالية والعسكرية للحد من تدفقات المهاجرين، خاصة بعد انزلاق البلاد في أتون حرب أهلية يغذيها التنافس الدولي والإقليمي على المصالح، وخير دليل على ذلك التنافس الفرنسي - الإيطالي على المصالح في الساحة الليبية، وهو ما ينجم عنه تعقيد في الوضع الداخلي الليبي.

بناء عليه، تتطلب المعالجة الجذرية لأزمة الهجرة في ليبيا استراتيجية أوروبية موحدة، تتوجه بالأساس نحو دعم حكومة مركزية في ليبيا حتى تكون قادرة على ضبط الأمن والاستقرار، ودعم عملية بناء مؤسسات الدولة المدنية 
والعسكرية، ومساعدة السلطات الليبية في جمع سلاح الميليشيات والكتائب المنتشرة في المدن والبلدات الليبية ودمجها ضمن قوات شرطية أو عسكرية نظامية تتبع للحكومة المركزية، وإصلاح قطاع القضاء والعدل وإصدار

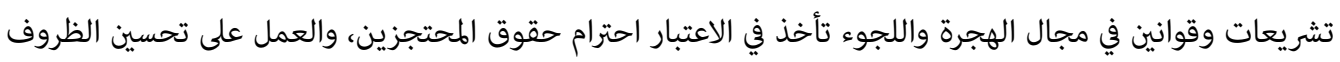
المعيشية للمهاجرين وللمحتجزين في مراكز الإيواء. وهناك ضرورة التنسيق مع دول الجوار الجغرافي وتعزيز التعاون

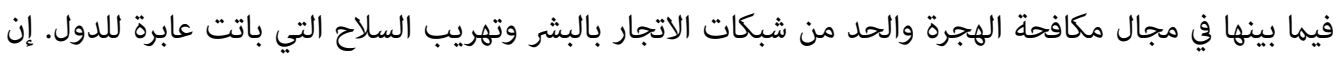

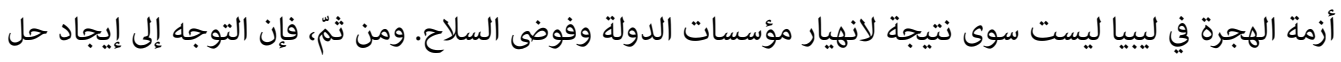

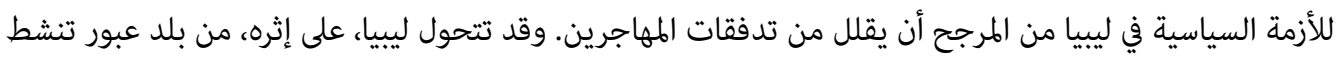

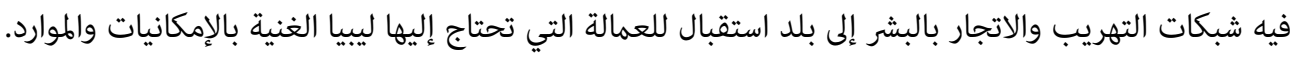




\begin{abstract}
العربية
الأثقر، جلبير. انتكاسة الانتفاضة العربية: أعراض مرضية. بيروت: دار الساقي، 2016.
\end{abstract}

الأمم المتحدة والمنظمة الدولية للهجرة. تقرير الهجرة الدولية لعام 2015: الهجرة والنزوح والتنمية في المنطقة العربية. بيروت: لجنة الأمم المتحدة الاقتصادية والاجتماعية لغربي آسيا "الإسكوا"، 2015.

بعثة الأمم المتحدة في ليبيا ومفوضية الأمم المتحدة السامية لحقوق الإنسان. محتجزون ومجردون من إنسانيتهم:

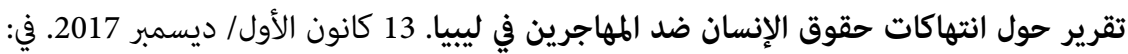
https://goo.gl/BYQa1S

التداعيات الجيوستراتيجية للثورات العربية. الدوحة/ بيروت: المركز العربي للأبحاث ودراسة السياسات، 2014. الدليمي، عباس فاضل. الموسوعة الميسرة في حقوق الإنسان. عمان: دار صفاء للنشر والتوزيع، 2016. منظمة العفو الدولية. شبكة التواطؤ المظلمة في ليبيا: الانتهاكات ضد اللاجئين والكهاجرين المتجهين إلى أوروبا. لندن:

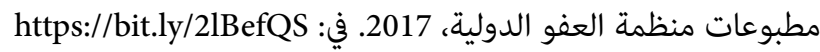

الأجنبية

"Action Plan of the Council and the Commission on How Best to Implement the Provisions of the Treaty of Amsterdam on an Area of Freedom, Security and Justice - Text adopted by the Justice and Home Affairs Council of 3 December 1998." Eur-Lex. 23/1/1999. at: https://bit.ly/2kxm8Gv Berdeloup, Sylvie \& Oliver Pliez. "Lybian Migration Corridor." European University Institute. Robert Schuman Center for Advanced Studies (2011). at: https://bit.ly/2mF2SHH

"Commission Regulation (EU) No 351/2010 of 23 April 2010 Implementing Regulation (EC) No 862/2007 of the European Parliament and of the Council on Community Statistics on Migration and International Protection as Regards the Definitions of the Categories of the Groups of Country of Birth, Groups of Country of Previous Usual Residence, Groups of Country of Next Usual Residence and Groups of Citizenship." Eur-Lex. 12/9/2019. at: https://bit.ly/2m74DNi

"Communication from the Commissionon Establishing a New Partnership Framework with Third Countries under the European Agenda on Migration." Eur-Lex. 7/6/2016. at: https://bit.ly/2nkcYxR "Communication from the Commission to the Council and the European Parliament - The Hague Programme: Ten Priorities for the Next Five Years the Partnership for European renewal in the field of Freedom, Security and Justice." Eur-Lex. 10/5/2005. at: https://bit.ly/21ZnMRq 
"Communication from the Commission to the European Parliament, the Council, the European Economic and Social Committee and the Committee of the Regions: A Dialogue for Migration, Mobility and Security with the Southern Mediterranean Countries." Eur-Lex. 24/5/2011. at: https://bit.ly/2kYx7sC

"Communication from the Commission to the European Parliament, the Council, the European Economic and Social Committee and the Committee of the Regions: The Global Approach to Migration and Mobility." Eur-Lex.18/11/2011. at: https://bit.ly/2mvWZMV

"Council Decision (CFSP) 2016/993 of 20 June 2016 Amending Decision (CFSP) 2015/778 on a European Union Military Operation in the Southern Central Mediterranean (EUNAVFOR MED operation SOPHIA)." Eur-Lex. 21/6/2016. at: https://bit.ly/2nb4rgY

"Council Decision of 14 May 2008 establishing a European Migration Network." Eur-Lex. 21/5/2008. at: https://bit.ly/2m7Gbvh

"Council Decisionon the Organization of Joint Flights for Removals from the Territory of Two or more Member States, of Third-country Nationals who are Subjects of Individual Removal Orders." Eur-Lex. 29/4/2004. at: https://bit.ly/2kks8SC

"Council Directive 2002/90/EC of 28 November 2002 Defining the Facilitation of Unauthorized Entry, Transit and Residence." Eur-Lex. 5/12/2002. at: https://bit.ly/2lQ1L7q

"Council Directive 2003/109/EC of 25 November 2003 Concerning the Status of Third-country Nationals who are Long-term Residents." Eur-Lex. 23/1/2004. at: https://bit.ly/2mmT5FW

"Council Directive 2003/86/EC of 22 September 2003 on the Right to Family Reunification." Eur-Lex. 3/10/2003. at: https://bit.ly/2mjnnt8

"Council Directive 2004/114/ECof 13 December 2004 on the Conditions of Admission of Thirdcountry Nationals for the Purposes of Studies, Pupil Exchange, Unremunerated Training or Voluntary Service." Eur-Lex. 23/12/2004. at: https://bit.ly/2kuhEAn

"Council Directive 2004/81/EC of 29 April 2004 on the Residence Permit Issued to Third-country Nationals who are Victims of Trafficking in Human Beings or who have been the Subject of an Action to Facilitate Illegal Immigration, who Cooperate with the Competent Authorities." EurLex. 29/4/2004. at: https://bit.ly/2lKkJfW

"Council Directive 2009/50/EC of 25 May 2009 on the Conditions of Entry and Residence of Third-Country Nationals for the Purposes of Highly Qualified Employment." Eur-Lex. 18/6/2009. at: https://bit.ly/2kWxOCK 
"Council Framework Decision of 28 November 2002 on the Strengthening of the Penal Framework to Prevent the Facilitation of Unauthorised Entry, Transit and Residence." Eur-Lex. 5/12/2002. at: https://bit.ly/2kImdqD

"Council Regulation (EC) No 377/2004 of 19 February 2004 on the Creation of an Immigration Liaison Officers Network." Eur-Lex. 2/3/2004. at: https://bit.ly/2mozmpn

"Council Regulation (EC) No 2007/2004 of 26 October 2004 Establishing a European Agency for the Management of Operational Cooperation at the External Borders of the Member States of the European Union." Eur-lex, 25/11/2004. at: https://bit.ly/2oypSZR

"Directive 2008/115/EC of the European Parliament and of the Council of 16 December 2008 on Common Standards and Procedures in Member States for Returning Illegally Staying Thirdcountry Nationals." Eur-Lex. 24/12/2008. at: https://bit.ly/2m2iuEK

"Regulation (EC) No 862/2007 of the European Parliament and of the Council of 11 July 2007 on Community Statistics on Migration and International Protection and Repealing Council Regulation (EEC) No 311/76 on the Compilation of Statistics on Foreign Workers." Eur-Lex. 31/7/2007. at: https://bit.ly/2kt4bJ3

"Regulation (EU) 2016/1624 of the European Parliament and of the Council of 14 September 2016 on the European Border and Coast Guard and Amending Regulation (EU) 2016/399 of the European Parliament and of the Council and Repealing Regulation (EC) No 863/2007 of the European Parliament and of the Council, Council Regulation (EC) No 2007/2004 and Council Decision 2005/267/EC." Eur-lex. 16/9/2016. at: https://bit.ly/2or6UUP

"Regulation (EU) No. 604/2013 of the European Parliament and of the Council of 26 June 2013 Establishing the Criteria and Mechanisms for Determining the Member State Responsible for Examining an Application forInternational Protection Lodged in one of the Member States by a Third-country National or a Stateless Person (recast)." Eur-Lex. 29/6/2013. at:https://bit.ly/2mfa3X6 "Tampere European Council 15 and 16 October 1999: Presidency Conclusions," Archive of European Integration, University of Pittsburgh, 15-16/11/1999. at: https://bit.ly/2SDHOLL

The European Court of Human Rights, Case of Hirsi Jamaa and Others v. Italy: (Application no. 27765/09). 23/2/2012. at: https://bit.ly/2n0UxL9

"The Stockholm Programme - An Open and Secure Europe Serving and Protecting the Citizens." Council of the European Union. 1/12/2009. at: https://bit.ly/2mprTX3

The UN Migration Agency. Libya's Migrant Report, Round 17: Flow Monitoring. Displacement Tracking Matrix (January-February 2018). at: https://goo.gl/BCoHUY 
IDP and Returnee Report, Round 26: Libya Mobility Tracking. Displacement Tracking Matrix (June-July 2019). at: http://bit.ly/2OwEzYh

"Treaty establishing the European Community." Eur-Lex. 31/8/1992. at: https://goo.gl/x6wr4b

Van Evera, Stephen. Causes of War: Power and Roots of Conflict. Ithaca, NY: Cornell University Press, 1999.

الملحق (1)

خريطة تدفقات المهاجرين من الدول الأفريقية

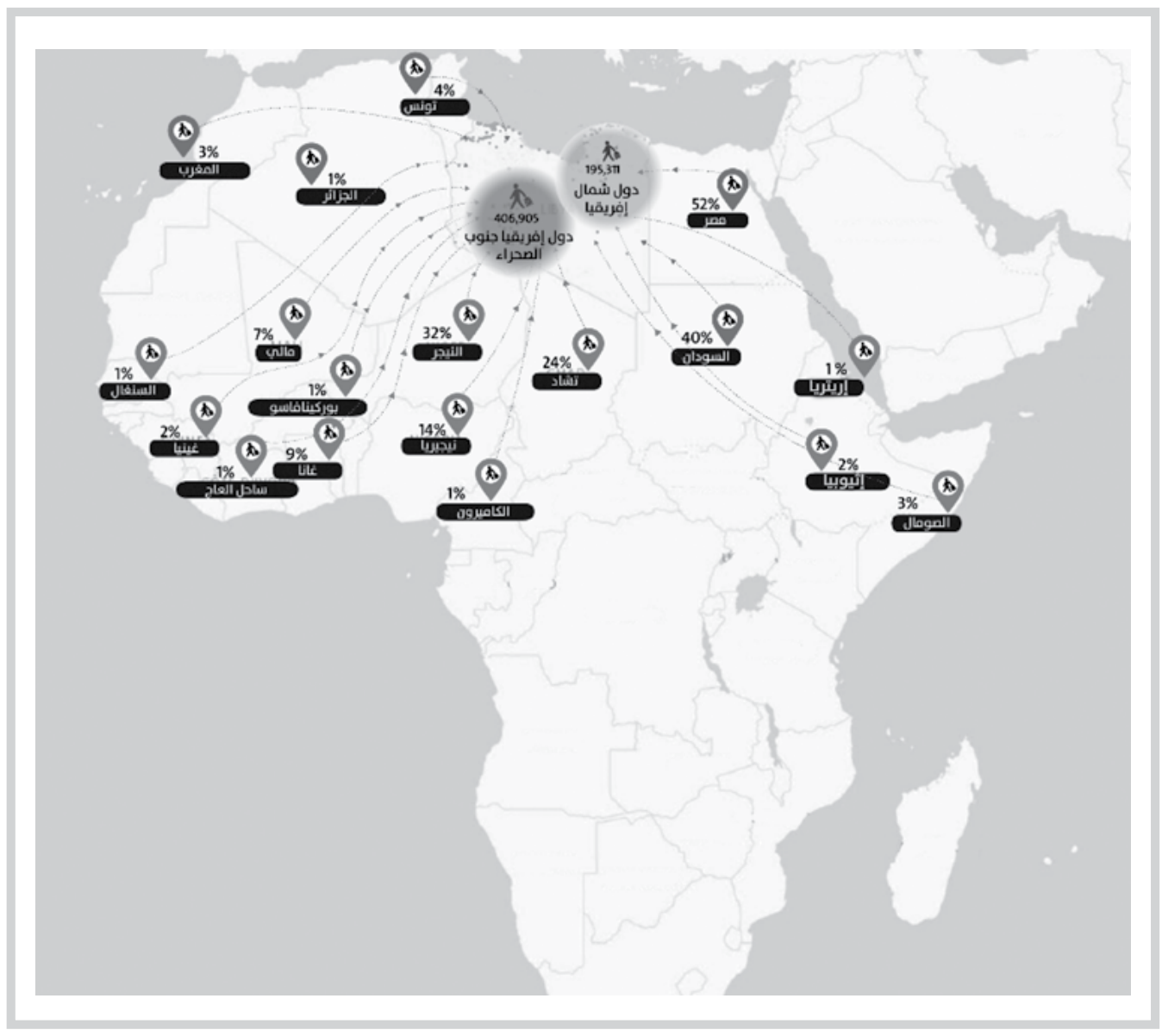

|

The UN Migration Agency, IDP and Returnee Report, Round 26: Libya Mobility Tracking, Displacement Tracking Matrix (June-July 2019), accessed on 9/9/2019, at: http://bit.ly/2OwEzYh 
الملحق (2)

خريطة تدفقات المهاجرين من قارة آسيا

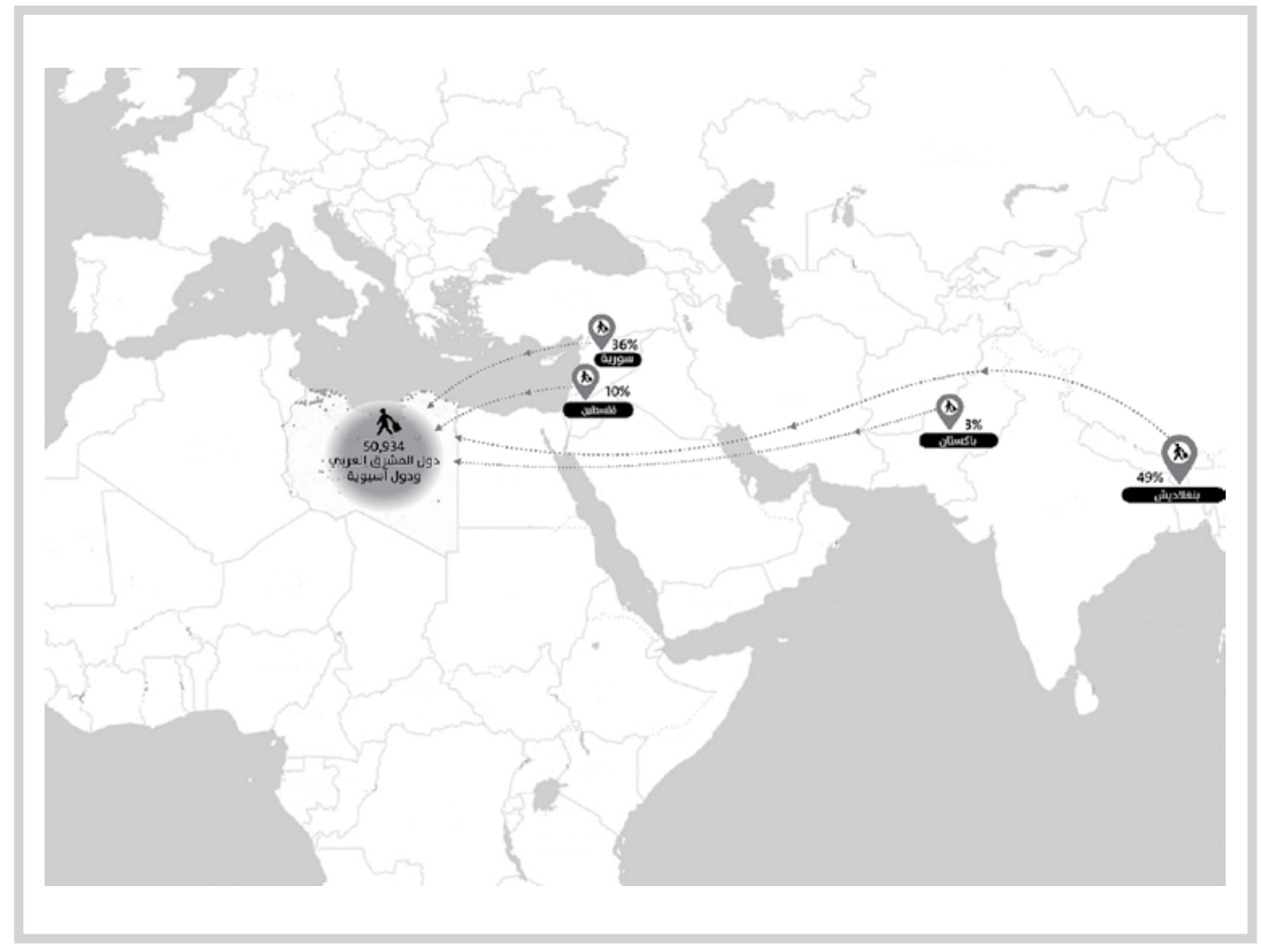

المصدر:

Ibid. 